\title{
Strategies to Enhance Periplasmic Recombinant Protein Production Yields in Escherichia coli
}

\author{
Alexandros Karyolaimos and Jan-Willem de Gier* \\ Department of Biochemistry and Biophysics, Stockholm University, Stockholm, Sweden
}

\section{OPEN ACCESS}

Edited by:

Dong-Yup Lee,

Sungkyunkwan University, South

Korea

Reviewed by:

Dave Siak-Wei Ow,

Bioprocessing Technology Institute (A*STAR), Singapore

Georgios Skretas,

National Hellenic Research

Foundation, Greece

Matthew Peter DeLisa,

Cornell University, United States

*Correspondence: Jan-Willem de Gier degier@dbb.su.se

Specialty section: This article was submitted to

Synthetic Biology,

a section of the journal Frontiers in Bioengineering and

Biotechnology

Received: 18 October 2021 Accepted: 24 November 2021 Published: 14 December 2021

Citation:

Karyolaimos $A$ and de Gier J-W (2021) Strategies to Enhance Periplasmic Recombinant

Protein Production Yields in

Escherichia coli.

Front. Bioeng. Biotechnol. 9:797334.

doi: 10.3389/fbioe.2021.797334
Main reasons to produce recombinant proteins in the periplasm of $E$. coli rather than in its cytoplasm are to -i- enable disulfide bond formation, -ii- facilitate protein isolation, -iiicontrol the nature of the $\mathrm{N}$-terminus of the mature protein, and -iv- minimize exposure to cytoplasmic proteases. However, hampered protein targeting, translocation and folding as well as protein instability can all negatively affect periplasmic protein production yields. Strategies to enhance periplasmic protein production yields have focused on harmonizing secretory recombinant protein production rates with the capacity of the secretory apparatus by transcriptional and translational tuning, signal peptide selection and engineering, increasing the targeting, translocation and periplasmic folding capacity of the production host, preventing proteolysis, and, finally, the natural and engineered adaptation of the production host to periplasmic protein production. Here, we discuss these strategies using notable examples as a thread.

Keywords: Escherichia coli, periplasm, recombinant protein, protein production, production optimization

\section{INTRODUCTION}

In 1972, the creation of the first recombinant DNA molecules was reported (Jackson et al., 1972). Not long thereafter, a study describing the "Construction of Biologically Functional Bacterial Plasmids In Vitro" was published (Cohen et al., 1973). Together with the development of methodology to chemically synthesize DNA, these two studies paved the way for using Escherichia coli as a host for producing recombinant proteins (Itakura et al., 1977). In 1976, the company Genentech-its name is a play of words of "genetic engineering" and "technology"-was founded and it pioneered the use of E. coli for the production of therapeutic proteins (Hughes, 2011). The foundation of Genentech is widely considered as the start of recombinant DNA driven biotechnology. Based on a collaborative effort between Genentech and Eli Lilly, human insulin (a.k.a. humulin), became in 1982 the first recombinantly produced therapeutic protein approved by the FDA for human use (Crea et al., 1978; Goeddel et al., 1979). For the production of humulin, the A and B chains of insulin were produced in the cytoplasm of two different $E$. coli strains as C-terminal fusions to $\beta$-galactosidase (Figure 1). After partial purification of the chimeric proteins, the insulin chains were released from the fusion proteins by cyanogen treatment. Subsequently, the released A and B chains were purified and joined through air oxidation resulting in functional insulin.

First, recombinant proteins, like above mentioned $\beta$-galactosidase insulin fusion proteins, were produced in the cytoplasm of E. coli (e.g., (Itakura et al., 1977; Goeddel et al., 1979)). Later on, based on increasing knowledge of protein export in $E$. coli, recombinant proteins were also produced in the periplasm of E. coli (e.g., (Fraser and Bruce, 1978; Talmadge et al., 1980)). What are the (potential) benefits of producing a protein in the periplasm of $E$. coli rather than in its cytoplasm? 


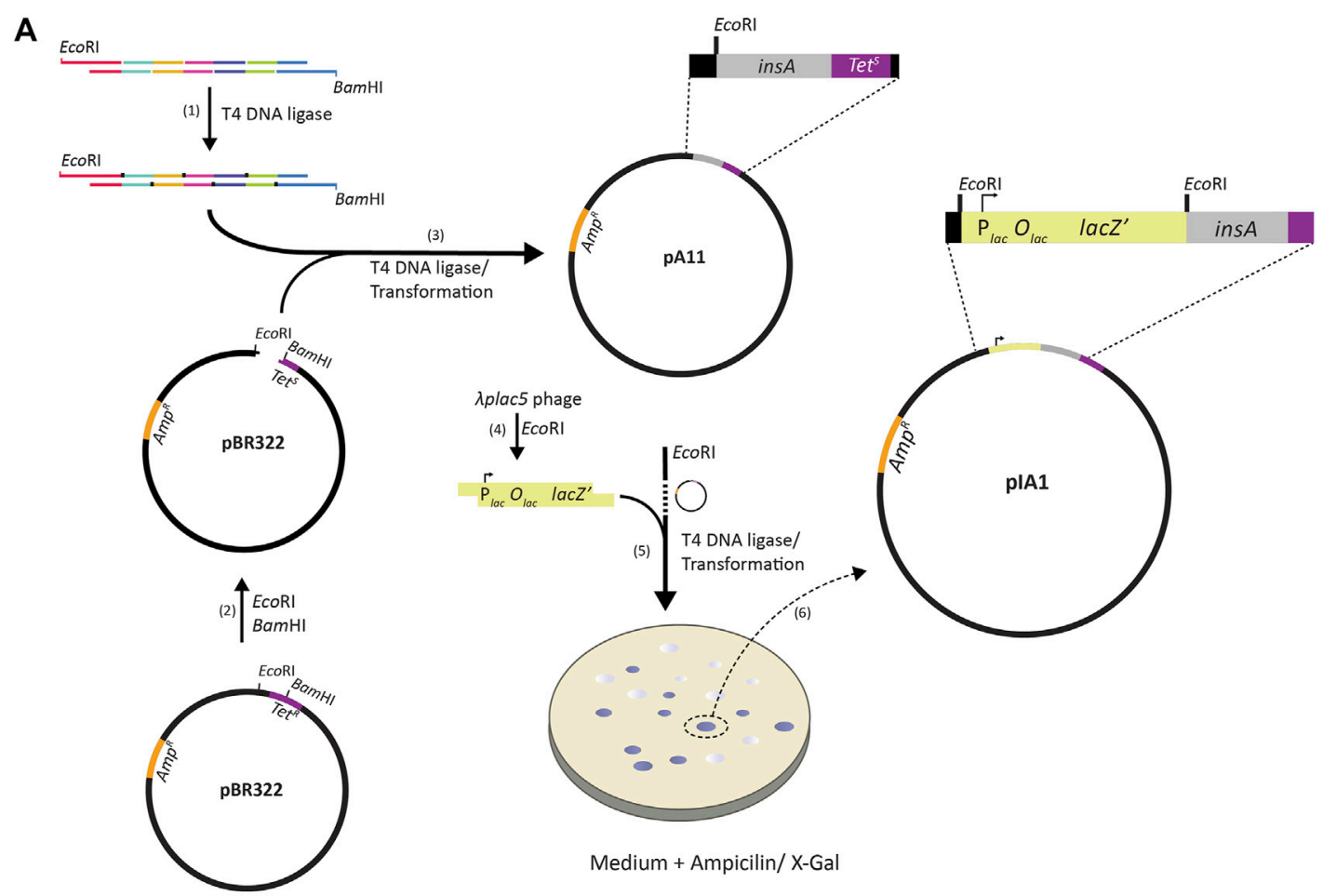

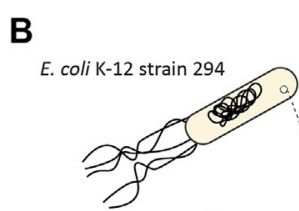

(1)

Constitutive production of B-galactosidase-Insulin chain A (No IPTG)

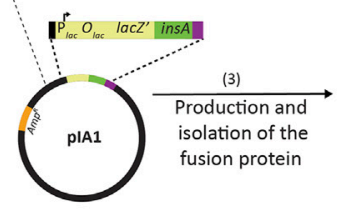

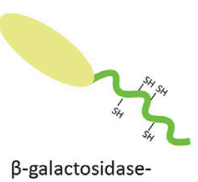
Insulin chain A

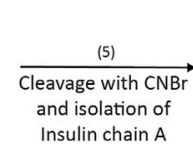

Insulin chain A
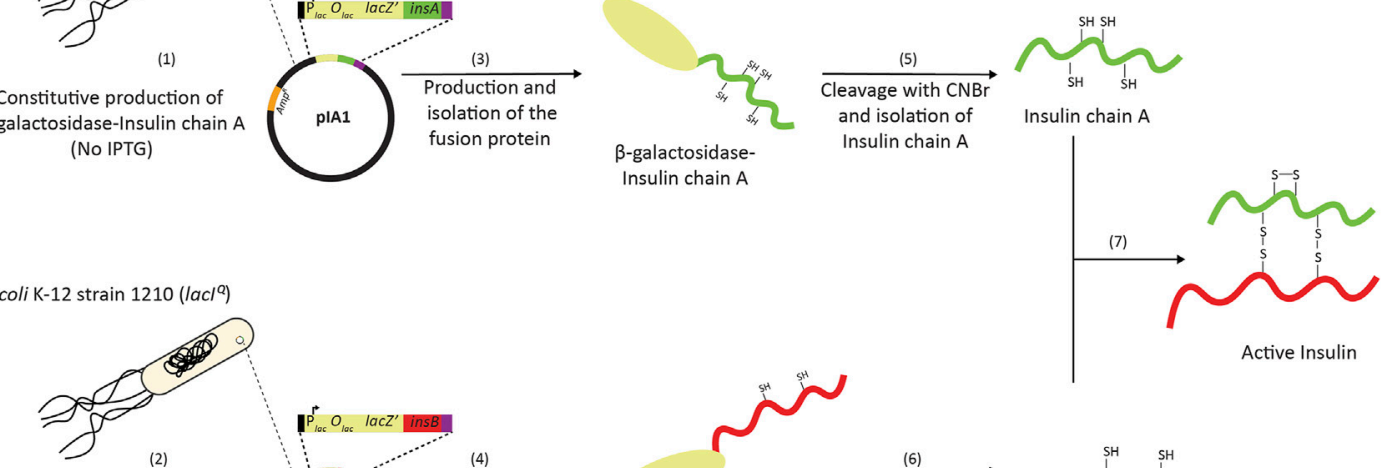

Induction of $\beta$-galactosidaseInsulin chain B production with IPTG

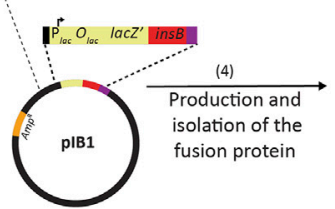

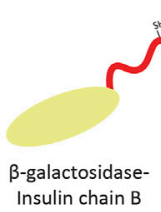

\section{N}

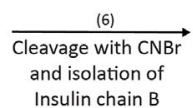

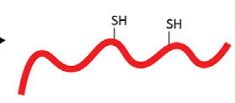

Insulin chain B

FIGURE 1 | Cloning and production of human insulin using E. coli. (A). The gene encoding the insulin A chain was constructed using DNA oligos with overlapping parts and T4 DNA ligase (1). EcoRl and BamHI compatible overhangs were introduced to the $5^{\prime}$ end and $3^{\prime}$ end of the ins $A$ gene, respectively. The overhangs were introduced to facilitate cloning of the insA gene into the pBR322 vector that had been digested with $E c o R I$ and BamHI (2). After ligation and transformation (3), positive clones were selected on antibiotic containing media; cells containing the pBR322 vector with the ins $A$ insert are ampicillin resistant, Amp ${ }^{R}$, and tetracycline sensitive, Tet ${ }^{\mathrm{S}}$, since the insertion of insA into pBR322 results in the partial deletion of the tet gene. Insertion of the insulin chain gene into pBR322 was verified by DNA sequencing. Subsequently, an EcoRI fragment from the bacteriophage $\lambda$ plac5 genome (4) containing the lac promoter, the lac operator and 1,006 codons of the lac $Z$ gene (out of the 1,024 codons encoding full length $\beta$-galactosidase) was inserted into the EcoRI site of the pBR322 vector with the ins $A$ gene (5). This results in the inframe fusion of $l a c Z$ and ins $A$ enabling the production of a $\beta$-galactosidase insulin chain $A$ fusion protein. Plates with medium containing ampicillin and the $\beta$-galactosidase substrate 5-bromo-4-chloro-3-indolyl- $\beta$-D-galactopyranoside (X-Gal) was used to identify blue colonies, i.e., colonies that could produce the $\beta$-galactosidase insulin A fusion protein (6). An expression vector for the production of a $\beta$-galactosidase insulin chain B fusion was constructed in a similar way. (B) The A and $B$ chains of insulin C-terminally fused to $\beta$-galactosidase were produced in the cytoplasm using two different $E$. coli strains. E. coli K-12 strain 294 was used for the production of the $\beta$-galactosidase-InsA fusion (1) and E. coli K-12 strain D1290 was used for the production of the $\beta$-galactosidase-InsB fusion (2). E. coli K-12 strain 294 produces the $\beta$-galactosidase-InsA fusion constitutively, so no Isopropyl $\beta$-D-1-thiogalactopyranoside (IPTG) was used to induce the expression of the gene encoding the fusion. The E. coli K-12 strain D1290 contains a mutation in the promoter of the lacl gene (lacl $\left.{ }^{Q}\right)$, which results in higher production of Lacl. Here, IPTG had to be added to induce expression of the gene encoding the fusion protein. After partial purification of the fusion proteins $(3,4)$, the insulin chains were recovered from the fusion proteins by cyanogen treatment $(\mathbf{5}, \mathbf{6})$. Subsequently, the A and B chains were isolated and joined through air oxidation resulting in active insulin $\mathbf{( 7 ) . ~}$ 
To reach the periplasm, a protein has to be equipped at its $\mathrm{N}$-terminus with a cleavable signal peptide so that it can cross the cytoplasmic membrane (Hegde and Bernstein, 2006; Smets et al., 2019). Upon translocation across the membrane, the signal peptide is cleaved off. This enables to control which amino acid is at the very $\mathrm{N}$-terminus of the mature protein (Smets et al., 2019). Not all proteins naturally contain a methionine at their $\mathrm{N}$-terminus and the cytoplasmic production of a protein in the cytoplasm does not guarantee the presence of an N-terminal methionine due to the action of methionine aminopeptidase (Liao et al., 2004; Frottin et al., 2006). Removal of the $\mathrm{N}$-formyl methionine can be critical for the proper folding, stability and function of a recombinant protein (Endo et al., 2001; Liao et al., 2003).

Protein production in the periplasm enables to isolate the protein from the periplasmic fraction rather than a whole cell lysate. This can greatly facilitate the isolation of a protein since it has to be isolated from a mixture that is less complex (Mergulhao et al., 2005). In this respect it should be mentioned that it is relatively easy to isolate the periplasmic fraction of E. coli also at an industrial scale (Mergulhao et al., 2005; Ellis and Humphreys, 2014). Furthermore, periplasmic protein production can also lead to the "spontaneous" release of the protein into the extracellular milieu (Kastenhofer et al., 2021). The release of a protein into the extracellular milieu can also be promoted by actively making the outer membrane more permeable or by fusing the protein to a fusion partner that is naturally secreted into the extracellular milieu (Hsiung et al., 1989; Zhang et al., 2006; Natarajan et al., 2017; Gao et al., 2018)). Extracellular production of a (fusion) protein can even further facilitate protein isolation (Tripathi, 2016). Notably, the costs involved in the isolation of a protein usually make up a large part of the total production costs (Tripathi and Shrivastava, 2019).

Many recombinant proteins, like hormones and antibody fragments, contain disulfide bonds which are essential for stabilizing the fold of a protein (Manta et al., 2019). Disulfide bond formation is not promoted in the reducing environment of the cytoplasm (Manta et al., 2019). However, the oxidative environment of the periplasm along with the presence of the disulfide bond formation (Dsb)-system in the periplasm promotes disulfide bond formation in this compartment, thereby facilitating the production of disulfide bond containing proteins (Manta et al., 2019). Finally, periplasmic protein production can promote the stability of a protein due to minimizing its exposure to cytoplasmic proteases (e.g., (Talmadge and Gilbert, 1982)).

However, the production of a protein in the periplasm is often cumbersome. Usually, a significant fraction of the produced protein accumulates in the unprocessed form in the cytoplasm (Schlegel et al., 2013; Baumgarten et al., 2018; Karyolaimos et al., 2019; Karyolaimos et al., 2020). Periplasmic protein production can also have a negative effect on the fitness of the production host and consequently biomass formation as well as protein production yields (Schlegel et al., 2013; Baumgarten et al., 2018). Furthermore, proteins produced in the periplasm do not always fold properly and can also be prone to degradation (e.g., (Meerman and Georgiou, 1994; Chen et al., 2004; Ellis et al., 2017)).

In this review, we give an overview of the different strategies used to promote proper targeting, efficient translocation, proper folding and avoid degradation of a protein when attempting to produce it in the periplasm of $E$. coli. We also discuss potential strategies to further enhance protein production yields in the periplasm.

\section{EXPORT OF PROTEINS FROM THE CYTOPLASM TO THE PERIPLASM}

To set the stage for this review, we will first briefly summarize how proteins are exported from the cytoplasm to the periplasm in E. coli. A secretory protein is synthesized in the cytoplasm and has at its N-terminus a cleavable signal peptide that targets it to either the Sec-translocon or the Tat-translocon in the cytoplasmic membrane (Frain et al., 2019; Oswald et al., 2021) (Figure 2). In E. coli, the vast majority of secretory proteins is translocated across the cytoplasmic membrane via the Sec-translocon (Smets et al., 2019). During translocation via the Sec-translocon, secretory proteins are in an unfolded conformation (De Geyter et al., 2016). Proteins translocated across the cytoplasmic membrane via the Tat-translocon fold in the cytoplasm prior to their translocation across the cytoplasmic membrane (Frain et al., 2019; Palmer and Stansfeld, 2020). Upon their translocation the signal peptide is cleaved off from both Sec- and Tat-dependent proteins.

\section{Protein Targeting}

The targeting of proteins to the Sec-translocon can occur either co-translationally via the Signal Recognition Particle (SRP)pathway or post-translationally in a chaperone-dependent or -independent manner (Tsirigotaki et al., 2017; Smets et al., 2019) (Figure 2). The SRP-pathway comprises the signal recognition particle (SRP), which is a ribonucleoprotein particle consisting of the $4.5 \mathrm{~S}$ RNA and the Ffh protein, and its receptor FtsY (Oswald et al., 2021). The cytoplasmic chaperones SecB and Trigger Factor (TF) can assist the posttranslational targeting of proteins (Smets et al., 2019; De Geyter et al., 2020). SecB can bind to a subset of secretory proteins and keeps them in a translocation-competent state (Sala et al., 2014). $\mathrm{TF}$, which plays a key role in the folding of cytoplasmic proteins, can also keep secretory proteins in a translocation-competent state and together with $\mathrm{SecB}$ aid their export (De Geyter et al., 2020). Targeting of (folded) proteins to the Tat-translocon is mediated by the presence of a signal peptide that contains a highly conserved twin-arginine motif (Sargent et al., 1998; Weiner et al., 1998; Frain et al., 2019; Palmer and Stansfeld, 2020).

\section{Protein Translocation}

The core of the Sec-translocon consists of the membrane proteins SecY and SecE (Oswald et al., 2021) (Figure 2). Together they form a protein-conducting channel in the cytoplasmic membrane (Oswald et al., 2021). In the absence of SecE, SecY is degraded by the cytoplasmic membrane protease FtsH (Ito and Akiyama, 2005). The peripheral ATP-dependent motor protein SecA 


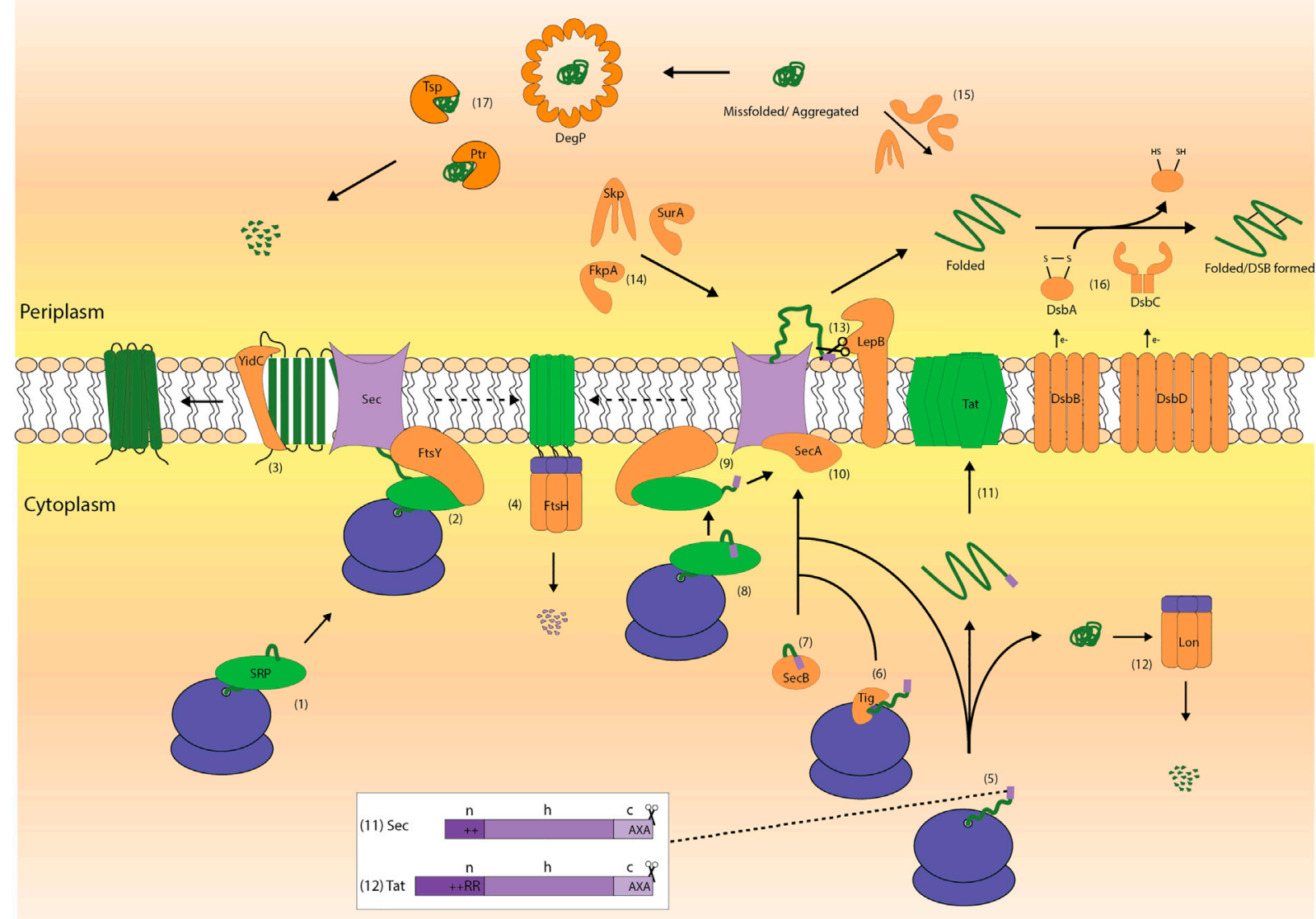

FIGURE 2 | The biogenesis of membrane and secretory proteins in E. coli. Membrane and secretory proteins are synthesized in the cytoplasm by the ribosome (1, 5). Most membrane proteins and some secretory proteins are targeted to the Sec-translocon via the SRP-pathway, which comprises the SRP and its receptor FtsY (1-2, 8-9). The membrane protein YidC, which is an insertase/chaperone, can assist the biogenesis of membrane proteins in conjunction with the Sec-translocon as well as an independent entity (3). Many secretory proteins are targeted post-translationally to the Sec-translocon in a chaperone-independent $(\mathbf{5}, \mathbf{1 0})$ or -dependent manner

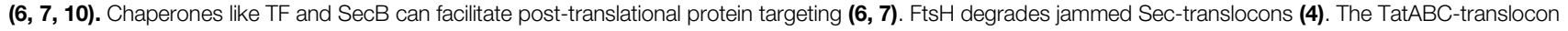
mediates the translocation of folded proteins with a signal peptide containing the twin arginine motif (11). Precursor proteins that get stuck in the cytoplasm can be degraded by cytoplasmic proteases like Lon (12). The motor protein SecA pushes secretory proteins through the Sec-translocon channel (10). Upon translocation of a protein across the cytoplasmic membrane LepB cleaves off the signal peptide (13). Periplasmic folding modulators like SurA, Skp and FkpA catalyze the folding of proteins in the periplasm $(\mathbf{1 4}, \mathbf{1 5})$. In the periplasm, the Dsb-system, which consists of DsbA, B, C and D, mediates the formation of disulfide bonds $(\mathbf{1 6})$ and proteins can be degraded by proteases like DegP, Tsp and Ptr (17).

pushes secretory proteins through the Sec-translocon channel (Smets et al., 2019; Oswald et al., 2021). The mode of translocation through the Sec-translocon can affect how a protein folds in the periplasm (Kadokura and Beckwith, 2009). The membrane protein YidC, which is an insertase/chaperone, can assist the biogenesis of membrane proteins in conjunction with the Sec-translocon as well as an independent entity (Shanmugaw and Dalbey, 2019). The E. coli Tat-translocon comprises multiple copies of the membrane proteins TatA, TatB and TatC (Sargent et al., 1998; Weiner et al., 1998; Frain et al., 2019). The assembly of the Tat-translocon is dynamic and is triggered by a Tat substrate interacting through its signal peptide with the TatBC-receptor complex (Frain et al., 2019). The Tat- translocon has a quality-control mechanism that prevents translocation of not properly folded proteins (Frain et al., 2019).

Notably, the protein flux through the Tat-translocon is considerably lower than through the Sec-translocon. It takes a few minutes to translocate a Tat-dependent protein versus a few seconds for a Sec-dependent protein (Taw et al., 2021). The proton-motive force is required for both efficient Sec- and Tatmediated protein export (Frain et al., 2019; Oswald et al., 2021).

\section{Protein Folding and Degradation}

Upon translocation of a protein across the cytoplasmic membrane, signal peptidase I (LepB) cleaves off the signal peptide (Paetzel, 2014) (Figure 2). In the periplasm there are 
folding modulators that can assist the folding of Sec-dependent proteins (Stull et al., 2018). Proteins that require disulfide bonds are reduced when they are exported from the cytoplasm to the periplasm via the Sec-translocon (De Geyter et al., 2016; Smets et al., 2019). In the periplasm, the Dsb-system, which consists of DsbA, B, C and D, mediates the formation of disulfide bonds (Manta et al., 2019). Oxidized DsbA transfers its own disulfide bond to its substrate proteins and is reduced in the process. The membrane protein DsbB re-oxidizes DsbA and it donates the electrons it has received from DsbA to the respiratory chain. DsbC can recognize if the substrate protein is not properly oxidized by DsbA. DsbC either isomerizes substrates that are not properly oxidized to their native state or reduces them thereby allowing DsbA to have another go to introduce a proper disulfide bond. The membrane protein DsbD maintains DsbC in its active reduced state. DsbD receives its electrons from the cytoplasmic thioredoxin $\operatorname{TrxA}$, which receives its electrons from NADPH. Other examples of periplasmic folding modulators are FkpA, which is a periplasmic chaperone/ peptidyl-prolyl isomerase (PPIase), SurA, which is a chaperone/PPIase, and the chaperone Skp (Stull et al., 2018). It should be noted that our grasp of the repertoire of periplasmic folding modulators and folding modulator-substrate specificity is still rather poor (Stull et al., 2018). The same holds for periplasmic proteases and periplasmic protease-substrate specificity (Merdanovic et al., 2011).

\section{Signal Peptides}

A signal peptide consists of a positively charged N-terminal region (n-region), an apolar hydrophobic core (h-region) and a more polar C-terminal region (c-region) (Izard and Kendall, 1994; Tsirigotaki et al., 2017). The c-region contains an AXA motif (Paetzel, 2014). This motif is recognized by LepB, which cleaves off the signal peptide upon protein translocation across the membrane (Paetzel, 2014). As mentioned before, Tatdependent signal peptides contain a conserved twin arginine motif in the n-region, at the boundary with the h-region (Frain et al., 2019). The hydrophobicity of the h-region of signal peptides that guide secretory protein to the Sec-translocon plays an important role in the mode of targeting (e.g., (Rusch and Kendall, 1994; Chen et al., 1996; Rusch et al., 2002)). It has been shown that increasing the hydrophobicity of the h-region of a signal peptide can funnel proteins that are normally targeted post-translationally into the co-translational SRP-pathway and vice versa (Kim et al., 2001). Furthermore, it has been shown that targeting of an export-defective protein can be rescued by increasing the hydrophobicity of the h-region (Rusch and Kendall, 1994). By funneling the protein into the cotranslational SRP-pathway the premature folding of the protein in the cytoplasm is most likely prevented (Rusch and Kendall, 1994). Signal peptides of post-translationally targeted proteins can help to delay the folding of the mature domain in the cytoplasm (Tsirigotaki et al., 2018). Recently, it has been shown that post-translational targeting/translocation is not only mediated by the signal peptide, but also by the so-called mature domain targeting sites in the mature part of the preprotein that can also bind to SecA (Chatzi et al., 2017; Smets et al., 2019).

\section{STRATEGIES TO ENHANCE PERIPLASMIC PROTEIN PRODUCTION YIELDS}

Strategies to enhance periplasmic protein production yields have focused on harmonizing protein production rates with the capacity of the secretory apparatus by transcriptional and translational tuning, by signal peptide selection and engineering, by increasing the targeting, translocation and periplasmic folding capacity of the cell, by preventing proteolysis, and by natural and engineered adaptation of the production host. Using notable examples as a thread, we will go through the different strategies used to enhance periplasmic protein production yields. Importantly, if the reader contemplates to use a certain strategy to enhance periplasmic protein production yields, the technical setup used to implement the strategy should be carefully considered.

\section{Tuning Transcription and Translation}

Studies aiming to enhance membrane protein production yields in E. coli have played a key role in identifying what can hamper periplasmic protein production. Therefore, first a brief introduction to these studies, in which the BL21(DE3) strain and $\mathrm{T} 7$ promoter-based expression vectors were used for protein production, will be given (Studier and Moffatt, 1986). In BL21(DE3), the expression of the gene encoding the target protein is driven by the bacteriophage T7 RNA polymerase (Studier and Moffatt, 1986). This polymerase transcribes approximately 5 times faster than $E$. coli RNA polymerase (Chamberlin et al., 1970; Studier and Moffatt, 1986). The T7 RNA polymerase specifically recognizes the $\mathrm{T} 7$ promoter governing the expression of the gene encoding the target protein (Studier and Moffatt, 1986). Expression of the chromosomally localized gene encoding the T7 RNA polymerase is governed by the IPTG-inducible lacUV5 promoter (Studier and Moffatt, 1986). This promoter is a more powerful variant of the wild-type lac promoter and it is not well titratable (Silverstone et al., 1970; Wanner et al., 1977). The idea behind this setup is that the more mRNA encoding the recombinant protein is synthesized, the more protein can be produced. In this respect it is good to mention that the system was developed for the production of soluble proteins in the cytoplasm (Studier and Moffatt, 1986).

The over-production of membrane proteins in BL21(DE3) is usually toxic (Wagner et al., 2007). However, many membrane proteins can be efficiently produced in the BL21(DE3)-derived, C41(DE3) and C43(DE3) strains (Miroux and Walker, 1996). Based on the observation that in the C41(DE3) and C43(DE3) strains the promoter governing the expression of $77 \mathrm{rnap}$ is weakened, the BL21(DE3)-derived Lemo21(DE3) strain was constructed (Wagner et al., 2008). In this strain, the activity of the T7 RNA polymerase can be precisely controlled by its natural inhibitor T7 lysozyme (Moffatt and Studier, 1987). The gene encoding the T7 lysozyme is on a plasmid under control of a rhamnose promoter. This promoter is titratable and covers a broad range of expression intensities (Giacalone et al., 2006). The combination of the lacUV5 promoter governing the expression of the gene encoding the T7 RNA polymerase and the rhamnose 
promoter governing the expression of the gene encoding T7 lysozyme, enables to tune the expression intensity of the gene encoding the target membrane protein from a 77 promoter-based expression vector (Wagner et al., 2008). As a consequence, the membrane protein production rate can be harmonized with the capacity of the membrane protein biogenesis apparatus of the cell using transcriptional tuning (Wagner et al., 2008; Schlegel et al., 2012). This results in cells in which the capacity of membrane protein biogenesis apparatus is not saturated. Therefore, these cells can efficiently produce membrane proteins (Wagner et al., 2008; Schlegel et al., 2012).

The Lemo21(DE3) strain was also used to test if saturation of the secretory apparatus can cause problems when attempting to produce proteins in the periplasm (Schlegel et al., 2013). Indeed, periplasmic protein production can also lead to saturation of the secretory apparatus. This results in poor periplasmic protein production yields and accumulation of the precursor target protein in the cytoplasm, poor growth, precursor accumulation of endogenous secretory proteins in the cytoplasm and the induction of the heat shock response, which is indicative for protein misfolding and mistargeting (Schlegel et al., 2013). Harmonizing the production rate of a secretory protein with the capacity of the secretory apparatus leads to more protein produced in the periplasm and strongly reduced negative effects (Schlegel et al., 2013). When the proteome composition of Lemo21(DE3) cells producing a single chain antibody fragment (scFv) under optimized conditions was compared with the proteome composition of Lemo21(DE3) cells with an empty expression vector, there were no notable differences (Baumgarten et al., 2018). Thus, the scFv could be efficiently produced in the periplasm without causing any notable stress or other side effects.

The rhamnose inducible promoter can also be used to directly express a gene encoding a protein (Giacalone et al., 2006; Hjelm et al., 2017). When the rhamnose promoter-mediated production of (cytoplasmic) super folder GFP was monitored in real-time using different amounts of rhamnose in E. coli wild-type cells, it became clear that the rhamnose concentration-dependent tunability is due to rhamnose consumption rather than regulating protein production rates (Hjelm et al., 2017). To regulate rhamnose promoter-mediated protein production rates in a rhamnose concentration dependent manner, a strain background in which both rhamnose catabolism as well as rhamnose uptake by the RhaT-transporter are abolished has to be used (Hjelm et al., 2017). Unfortunately, there is no straight forward explanation for this observation. Thus, using the rhamnose promoter in a rhamnose catabolism and rhaT deficient strain background enables harmonizing target protein production rates with the capacity of the secretory apparatus in a rhamnose concentration dependent manner (Hjelm et al., 2017). This setup has been used successfully to boost periplasmic protein production yields (Hjelm et al., 2017; Karyolaimos et al., 2019).

Researchers from Genentech reported in 1996 that the secretion of recombinant proteins into the periplasm of $E$. coli could be enhanced by optimizing translational levels rather than maximizing them (Simmons and Yansura, 1996) (Figure 3). The signal peptide from the E. coli heat-stable enterotoxin II (STII) in combination with the phosphate limitation inducible phoA promoter was used to produce a series of recombinant proteins in the periplasm (Chang et al., 1987; Simmons and Yansura, 1996). Notably, STII is targeted post-translationally to the Sec-translocon. To tune translational levels, the translational initiation region (TIR), which covers the immediate upstream part of the ribosome binding site to approximately 20 nucleotides downstream of the initiation codon, was modified (Goodman et al., 2013). More precisely, codons 2 to 6 of the STII signal peptide were modified without changing the amino acid sequence of the signal peptide to create a library of vectors with different translational strengths. Subsequently, the $E$. coli alkaline phosphatase (PhoA) was used as a reporter to characterize the library. This enabled to identify TIR variants covering a 10 -fold range of translational strength. These variants were used to enhance periplasmic protein production. Importantly, for each target tested a narrow translational range was required for optimal periplasmic protein production. Interestingly, when an optimal TIR had been identified for a target and the copy number of the expression vector used was increased, periplasmic protein production levels were strongly reduced and precursor material accumulated in the cytoplasm. At the time the authors could only speculate about the underlying mechanisms behind their findings. However, based on what we know now it is obvious that using different TIRs the production rate of a secretory recombinant protein can be harmonized with the capacity of the secretory apparatus, thereby enhancing periplasmic production yields. Increasing the copy number of the expression vector leads to increased protein production and, consequently, the detrimental saturation of the secretory apparatus (Schlegel et al., 2013; Baumgarten et al., 2018).

Taken together, harmonizing secretory protein production rates with the capacity of the secretory apparatus by transcriptional and translational tuning can lead to enhanced periplasmic protein production yields. To regulate secretory protein production rates at the transcriptional level, titratable promoter systems other than the ones described above can also be used (Meyer et al., 2019). To regulate secretory protein production rates at the translational level the ribosome binding site of a TIR can also be modified (Salis et al., 2009; Eichmann et al., 2019). Rather than using TIR libraries, screening approaches can also be used to identify a suitable TIR (Rennig et al., 2018). The T7 RNA polymerase-based RiboTite system, which was recently used to enhance protein production yields in the periplasm, is an example of a system that operates both at the transcriptional and translational level (Horga et al., 2018). In the RiboTite system, transcriptional control is mediated by an IPTGinducible promoter controlling t7rnap expression (Morra et al., 2016). Translational control in the system is mediated by an orthogonal riboswitch (Morra et al., 2016). This switch sequesters the ribosome binding site in the absence and releases it in the presence of pyrimido-pyrimidine-2,4-diamine.

\section{Signal Peptide Selection and Engineering}

With our current knowledge it is not possible to predict what signal peptide one should use to efficiently produce a protein in the periplasm of E. coli (Karyolaimos et al., 2019). Often people 

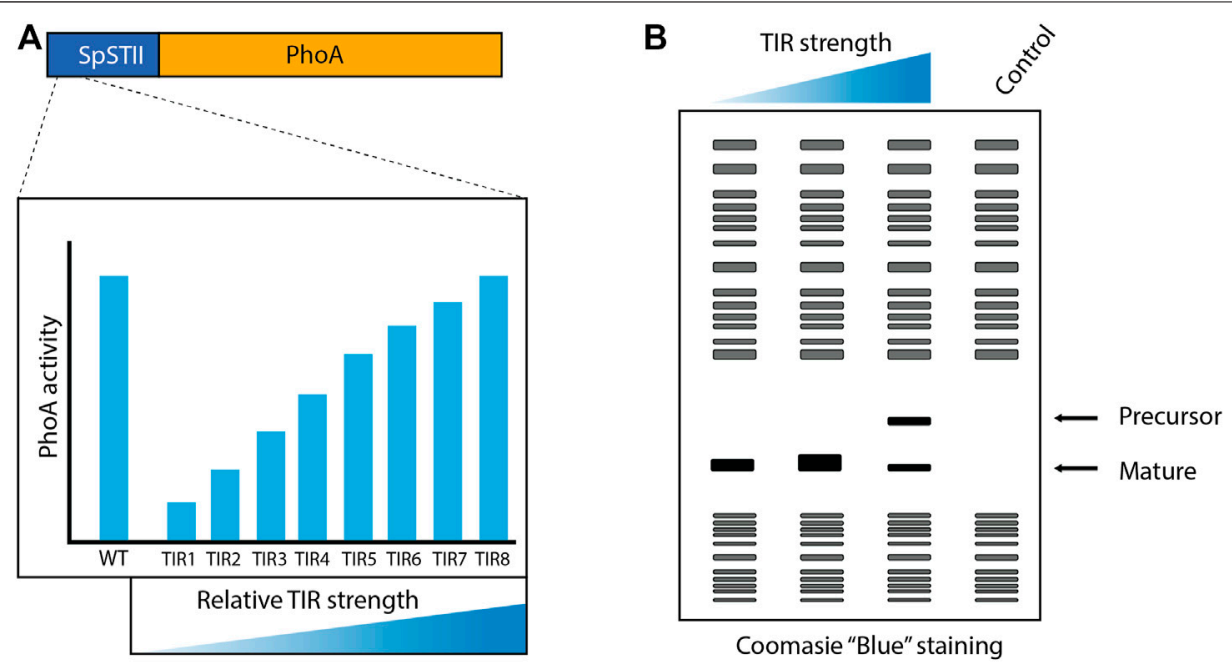

C

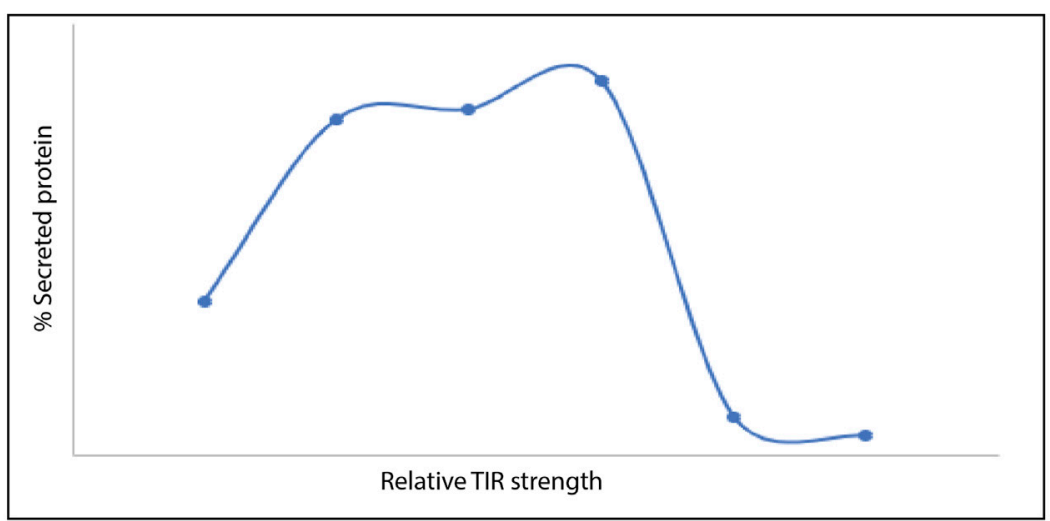

FIGURE 3 | Modifying the translational initiation region (TIR) to enhance recombinant protein production in the periplasm. (A) Codons 2 to 6 of the STII signal peptide were modified without changing the amino acid sequence of the signal peptide. The relative TIR strength of variants was assessed using PhoA as a reporter and TIR variants covering a 10-fold range of translational strength were identified. (B) Production of recombinant protein targets was tuned using the TIR library and protein production was assessed using SDS-PAGE and Coomassie Blue staining. This led to the identification of a TIR optimal for the production of a particular recombinant protein in the periplasm. (C) Mid-range relative TIR strengths lead in general to the highest periplasmic protein production yields.

use signal peptides from abundantly present native proteins or signal peptides that have successfully been used before for periplasmic protein production (Kendall et al., 1986; Schierle et al., 2003; Sijbrandi et al., 2003; Schlegel et al., 2013; Schmidt et al., 2016; Hjelm et al., 2017; Baumgarten et al., 2018; Karyolaimos et al., 2019). However, there is no guarantee that these signal peptides will also facilitate the efficient production of any other protein in the periplasm (Karyolaimos et al., 2019). Systematic screening or engineering approaches to identify signal peptides that enhance periplasmic protein production yields are scarce.

To improve the display levels of a series of proteins on filamentous phages, the Plückthun laboratory used a panel of signal peptides that promote co-translational as well as posttranslational targeting of phage coat protein fusions to the Sectranslocon (Steiner et al., 2006). Display levels of the proteins of interest were markedly higher when signal peptides promoting co-translational targeting were used and for some targets levels could be enhanced up to seven hundred fold. Co-translational targeting of the fusions may prevent folding of the protein of interest moieties in the cytoplasm, which would prevent translocation and the subsequent display of the fusions.

Importantly, not only signal peptides can significantly impact periplasmic protein production yields, but as discussed in the previous section also protein production rates. Therefore, our lab set up a combined screen involving four different signal peptides and varying production rates to produce a $s c F v$ and human growth hormone (hGH) in the periplasm (Karyolaimos et al., 2019) (Figure 4). The signal peptides from the E. coli DsbA, Hbp, OmpA and PhoA proteins were used to guide the two targets to the periplasm. DsbA is, as explained before, a periplasmic thiol: disulfide oxidoreductase and it is generally assumed that the DsbA signal peptide mediates the co-translational targeting of proteins (Schierle et al., 2003). The DsbA signal peptide has been widely and successfully used for the production of recombinant proteins in the periplasm (e.g., (Steiner et al., 2006)). The 


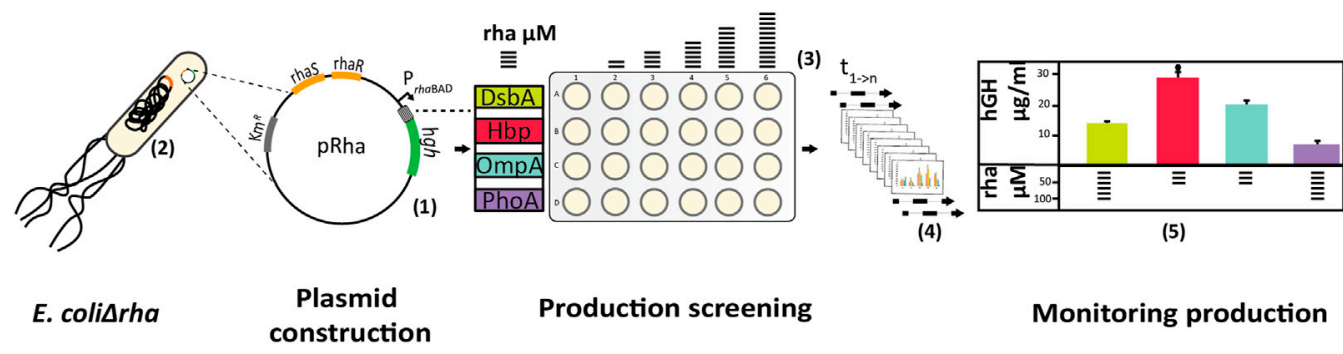

FIGURE 4 | Setup of the signal peptide and production rate-based combinatorial screening approach to enhance periplasmic protein production yields in $E$. coli. The gene encoding the recombinant protein to be produced (hGH) was fused to sequences encoding for the signal peptides from the $E$. coli proteins DsbA, OmpA, PhoA, and the $\mathrm{Hbp}$. The genetic fusions were subsequently inserted into the rhamnose promoter-based expression vector pRha (1). The vectors were transformed into E. colisrha (2). In E. colisrha, target production rates can be precisely tuned by varying the rhamnose concentration (3). Production screening of the periplasmically produced hGH was done in a 24-well setup and a range of rhamnose concentrations was used to induce the target gene expression (3). Following the induction, the cells from equal culture volumes were harvested at different time intervals and hGH production was monitored by means of fluorescent western blotting (4). The best conditions for each signal peptide combination were compared directly to determine the rhamnose concentration and signal peptide combination that provided the highest periplasmic yields of active hGH (5).

Hemoglobin protease (Hbp) is an abundantly produced autotransporter and is co-translationally targeted (Sijbrandi et al., 2003). OmpA is an outer membrane protein and targeted post-translationally in a SecB-dependent manner (Baars et al., 2006). PhoA is a periplasmic enzyme that catalyses the hydrolysis and transphosphorylation of a wide variety of phosphate monoesters and it has been reported that PhoA targeting can occur both post- and co-translationally (Kendall et al., 1986; Kadokura and Beckwith, 2009). The previously discussed rhamnose promoter (see section "Tuning transcription and translation") and a strain background in which the whole rha operon is deleted was used to produce the scFv and hGH equipped with the four different signal peptides at different production rates. Across the screen conditions, the periplasmic production yields of both targets varied a lot. The optimal signal peptide and rhamnose concentration differed for each protein. Interestingly, for scFv the OmpA signal and for hGH the Hbp signal peptide led to the best periplasmic production yields. Thus, the signal peptide from the post-translationally targeted OmpA protein and the signal peptide from a co-translationally targeted protein Hbp protein result in optimal periplasmic production of the $\mathrm{scFv}$ and $\mathrm{hGH}$, respectively. There is no straightforward explanation for this observation, but it stresses that signal peptides derived from post-translationally targeted proteins cannot be excluded a priori for efficient periplasmic protein production. This study also shows the importance of combinatorial screening approaches for enhancing periplasmic protein production yields.

Rather than trying to identify a suitable signal peptide for the periplasmic production of a protein in the periplasm, such a signal peptide can also be engineered. In a study from Genentech, signal peptide engineering was used to promote the secretion of the heavy chain of a monoclonal antibody (mAb) that was limiting the production of the $\mathrm{mAb}$ in the periplasm (Zhou et al., 2016). To improve the secretion of the heavy chain it was produced using different signal peptides at controlled TIR strengths. The use of the DsbA signal peptide resulted in the highest periplasmic production yields compared to the other signal peptides tested. A close inspection of the different signal peptides used showed that the hydrophobicity of the h-region of the DsbA signal peptide was higher than the hydrophobicity of the h-region of the other signal peptides. This raised the question if the hydrophobicity of the h-region of a signal peptide can play an important role in periplasmic protein production. To explore this the signal peptide of the aforementioned STII protein was used since its $\mathrm{n}$ - and c-regions are very similar to the same regions of the DsbA signal peptide. The hydrophobicity of the h-region of the STII signal peptide is lower and increasing the hydrophobicity of its h-region enhanced secretion of the heavy chain and periplasmic $\mathrm{mAb}$ production levels. Further increasing the hydrophobicity of the h-region did not result in further enhancing periplasmic production yields. Decreasing the hydrophobicity of the h-region of the DsbA signal resulted in the opposite effect. Thus, in this study promoting co-translational targeting led to enhanced periplasmic protein production.

In several studies it has been shown that the presence of rare codons in the genetic information encoding a signal peptide, especially in the region encoding the n-region, can have a positive impact on both periplasmic protein production yields and on proper protein folding (e.g., (Humphreys et al., 2000; Zalucki et al., 2008; Zalucki et al., 2010; Castiñeiras et al., 2018; Kulmala et al., 2019)). It is tempting to speculate that these rare codons make the TIR/protein translocation kinetics more amenable to efficient periplasmic protein production.

\section{Increasing the Capacity of the Secretory Apparatus Increasing Protein Targeting Capacity}

Co-producing the cytoplasmic chaperones GroEL and DnaK, which both have also been implicated in protein secretion, can facilitate periplasmic protein production (Hu et al., 2007; Makino et al., 2011b; Sonoda et al., 2011). Attempts to enhance periplasmic protein production yields by co-producing TF and SecB have not been successful (Puertas et al., 2010; Makino et al., 2011b). TF can hamper protein secretion by blocking access of the 
precursor protein to the secretory apparatus (De Geyter et al., 2020). It is possible that increased levels of SecB hamper secretion by retaining a secretory protein in the cytoplasm rather than promoting its secretion. Interestingly, the production of the secreted form of a leech carboxypeptidase inhibitor, targeted by the DsbA signal peptide to the Sec-translocon, is increased in a TF deficient strain background (Puertas et al., 2010). It is possible that in spite of using the DsbA signal peptide, targeting of the leech carboxypeptidase inhibitor occurs only partially cotranslationally due to limited SRP-pathway capacity. If this would be the case, the secretion of the target protein could indeed be hampered by TF. This scenario is supported by the observations that co-producing SRP (both Ffh as well as the 4.5S RNA) also increased production of the leech carboxypeptidase inhibitor. Moreover, combining a TF deficient strain background with the co-production of SRP had an additive effect on the production of secreted target protein and strongly reduced the accumulation of the precursor form of the target protein in the cytoplasm (Puertas et al., 2010). Co-production of components of the SRP-targeting pathway, including FtsY, have been widely used to facilitate the co-translational targeting of secretory recombinant proteins (e.g., (Lee et al., 2013)).

\section{Increasing Protein Translocation Capacity}

It has been shown that co-production of the Sec-translocon core components SecY and E can lead to increased periplasmic protein production yields (Makino et al., 2011b). However, when SecY and $\mathrm{E}$ were co-produced to increase periplasmic production of human interleukin-6 equipped with an OmpA signal peptide, periplasmic production yields were not increased (Pérez-Pérez et al., 1994). Interestingly, when a mutant version of SecY, i.e., PrlA4, was co-produced rather than wild-type SecY, the periplasmic production yield of human interleukin- 6 increased significantly. PrlA4 was isolated in a screen aiming at the isolation of suppressor mutations that could restore the export of LamB equipped with defective signal peptides (Emr et al., 1981). Coproduction of PrlA4 without SecE provided a three-fold increase in export of the target protein compared to the 10-fold increase when both SecE and PrlA4 were co-produced. Co-production of SecE with PrlA4 is most likely needed to prevent SecY/PrlA4 degradation by FtsH (Nijeholt et al., 2013). PrlA4 has not only been shown to enable the translocation of proteins with a defective signal peptide or without a signal peptide, but it also has been shown to have a higher binding affinity towards SecA (van der Wolk et al., 1998). This promotes binding of SecA as well as the precursor protein at the translocation site. This may improve the translocation efficiency of proteins the wild-type Sec-translocon has difficulties with translocating (van der Wolk et al., 1998).

The Tat pathway has also been used to produce proteins, including ones with disulfide bonds, in the periplasm of E. coli (e.g., (DeLisa et al., 2003; Matos et al., 2014; Alanen et al., 2015; Browning et al., 2017; Montero et al., 2019)). Co-producing the components of the Tat-translocon has been used successfully to increase the Tat-pathway capacity of E. coli, thereby enhancing Tat-mediated periplasmic protein production yields (Browning et al., 2017; Montero et al., 2019). To enhance the periplasmic production of properly folded disulfide bond containing proteins in E. coli, co-producing Tat-translocon components has been combined with the CyDisCo (Cytoplasmic Disulfide bond formation in E. coli) setup. The CyDisCo setup is based on the cytoplasmic production of a yeast mitochondrial thiol oxidase, Ervlp, and the human protein disulfide isomerase, PDI, both lacking signal peptides (Gaciarz et al., 2016).

Recently, Tat-translocons were isolated enabling high level periplasmic protein production (Taw et al., 2021). To isolate these translocons, cells with the native tat operon deleted and expressing a mutant library of tat $A B C$ operons and at the same time producing a $s c F v$ equipped with a Tat-dependent signal peptide and C-terminally fused to TEM- $\beta$ lactamase were put on plates containing a high amount of carbenicillin. This setup enabled to use growth for selecting cells with an increased Tat-export capacity and resulted in the isolation of three "supersecreting" Tat-translocons. These translocons not only mediated the efficient periplasmic production of the target used in the screen, but also of other proteins at levels that are higher than the ones obtained with the wild-type Tat-translocon. All three "super-secreting" Tat-translocons had mutations in the tat $B$ and tat $C$ genes and no mutations in the tat $A$ gene. Using targets that are rejected by the wild-type Tat-translocon it was shown that the quality-control mechanism that prevents translocation of not properly folded proteins in the mutant Tat-translocons appears to be more relaxed. This most likely enables an increased protein flux through these translocons. Importantly, this does not affect the quality of the in the periplasm produced proteins.

\section{Increasing Signal Peptide Processing Capacity}

Co-producing LepB, which cleaves off signal peptides upon protein translocation, can also increase periplasmic protein production yields (van Dijl et al., 1991). It has been shown that increasing the synthesis of protease IV (SppA) by modifying its TIR also results in enhanced periplasmic protein production (Gawin et al., 2020). SppA is a membrane-bound signal peptide peptidase that is required for maintaining proper protein secretion (Novak and Dev, 1988; Dalbey et al., 2012).

\section{Increasing Periplasmic Protein Folding Capacity}

Periplasmic folding modulators have also been co-produced to enhance periplasmic protein production yields. Co-production of one of the or both key players of the Dsb-system, i.e., DsbA and DsbC, has been widely used to enhance the production of disulfide bond containing proteins in the periplasm (e.g., (Joly et al., 1998; Schlapschy et al., 2006; Makino et al., 2011b; Sonoda et al., 2011)). Co-production of e.g., FkpA, SurA and Skp has also helped to enhance periplasmic and extracellular protein production yields (e.g., (Mavrangelos et al., 2001; Schlapschy et al., 2006; Hu et al., 2007; Makino et al., 2011a; Sonoda et al., 2011)). To facilitate the identification of folding modulators enhancing periplasmic protein production yields, expression vectors that enable the co-production of several folding modulators at the same time have been engineered (Schlapschy et al., 2006). It has been shown that culturing setups can determine what folding modulator has to be co- 
produced (Ellis et al., 2017). To enhance periplasmic production of an antibody fragment in small shake flasks FkpA had to be coproduced. However, in a high cell density fed-batch culture DsbC had to be co-produced. This observation raises the question if the co-production of a folding modulator can also have indirect positive effects. Indeed, it has been shown that co-producing folding modulators can have a positive effect on the fitness of E. coli, which also can help to enhance periplasmic protein production yields (Ow et al., 2010).

Most often two compatible expression vectors have been used for producing the folding modulator and the recombinant protein (e.g., (Joly et al., 1998; Schlapschy et al., 2006; Makino et al., 2011b; Sonoda et al., 2011)). Usually, different promoter systems are used to govern the expression of the genes encoding the folding modulator and the protein. The different promoter systems can also be used for the sequential production of a folding modulator and the protein (Joly et al., 1998; Makino et al., 2011b). Thus, cells can be pre-loaded with a folding modulator before the production of the protein is initiated. This better prepares cells for the production of the protein and lowers the risk of saturating the secretory apparatus. Also artificial operons containing the genes encoding both the folding modulator and the protein have been used (Ellis et al., 2017). This setup requires only one expression vector and one promoter system and is in particular useful for large scale protein production.

\section{Preventing Proteolysis}

An important reason to produce a protein in the periplasm is to minimize its exposure to cytoplasmic proteases (Talmadge and Gilbert, 1982). However, this does not mean that there are no proteases in the cell envelope which can negatively affect periplasmic protein production (Gottesman, 1996). Indeed, it has been shown that the three periplasmic proteases DegP, Tsp and Ptr, can negatively affect protein production yields in the periplasm (Meerman and Georgiou, 1994; Chen et al., 2004). Most work on the identification of proteases affecting periplasmic protein production yields was done at a time when these proteases were the main ones that had been characterized (Gottesman, 1996). Only little is known about their substrates and how they recognize them. Therefore, it cannot be predicted which protease or combination of proteases can negatively affect production yields of a particular protein in the periplasm. This makes that proteases interfering with periplasmic protein production have to be identified by screening protein production yields in protease deficient strains.

The serine endoprotease DegP was identified in a screen aiming at the isolation of mutations preventing the degradation of abnormal periplasmic proteins (Strauch and Beckwith, 1988). DegP may degrade transiently denatured, unfolded proteins and/or newly secreted proteins prior to folding and disulfide bond formation (Strauch et al., 1989; Laskowska et al., 1996; Skorko-Glonek et al., 1999; Soltes et al., 2017). Inactivation of DegP by deleting the $\operatorname{deg} P$ gene often results in improved periplasmic protein production yields (e.g., (Meerman and Georgiou, 1994; Champion et al., 2001; Chen et al., 2004)). DegP can also act as a chaperone (Meltzer et al.,
2009). The protease function of DegP can be inactivated by a simple point mutation without affecting its chaperone activity (Spiess et al., 1999). This mutation is often used to create DegP protease deficient strains that still have DegP chaperone activity (e.g., (Ellis et al., 2017)). Rather than deleting the gene encoding DegP or inactivating its protease function, periplasmic protein production yields have also been improved by lowering DegP levels. This was done by replacing the ribosome binding site in the TIR controlling $\operatorname{deg} P$ expression with a weaker one (Gawin et al., 2020).

Both Tsp and Ptr were first detected when attempting to identify cytoplasmic proteases suggesting that these two periplasmic proteases are abundantly present (Cheng et al., 1979; Swamy and Goldberg, 1981). Tsp can degrade proteins with nonpolar C-termini and based on this observation it was named Tail-specific protease (Keiler and Sauer, 1996). It has been reported that Tsp can degrade antibody light chain fragments (Chen et al., 2004; Ellis et al., 2017). Tsp is also involved in regulating peptidoglycan synthesis by degrading MepS, which is a murein endopeptidase participating in the expansion of the peptidoglycan sacculus during growth and morphogenesis (Singh et al., 2015). Deletion of the gene encoding Tsp impairs growth. Inactivating the mepS gene in a Tsp deficient background restores growth (Chen et al., 2004; Ellis et al., 2017). Ptr (Protease III) is a zinc metalloendopeptidase that has been shown to degrade insulin (Swamy and Goldberg, 1981; Becker and Roth, 1992; Ding et al., 1992).

OmpT is an outer membrane protease with specificity for paired basic residues and its catalytic site is facing the bacterial surface (Kramer et al., 2001). OmpT can degrade periplasmically produced proteins after cell lysis (Grodberg and Dunn, 1988; Akiyama and Ito, 1990). Since proteins produced in the periplasm are usually isolated or can leak in the extracellular medium often OmpT deficient production strains are used (Jeong et al., 2009; Studier et al., 2009; Jeong et al., 2015).

Proteases do not only negatively affect periplasmic protein production yields, they can also be required for efficient periplasmic protein production. Secretory proteins can get stuck in the Sec-translocon thereby jamming it (Jiang et al., 2021). The cytoplasmic membrane protease FtsH, which is a processive, ATP-dependent zinc metallopeptidase for both cytoplasmic and cytoplasmic membrane proteins, can clear jammed Sec-translocons (van Stelten et al., 2009). Furthermore, it has been shown that the cytoplasmic Lon protease can clear not properly targeted secretory proteins in the cytoplasm (Kihara et al., 1995; van Stelten et al., 2009). It has been proposed that the cytoplasmic peptidase, PrlC (oligopeptidase A) can remove signal peptides from not properly targeted secretory proteins, thereby setting the stage for their clearance (Conlin et al., 1992).

\section{Natural and Engineered Adaptation of the Production Host}

E. coli can respond to stress by changing its proteome composition (e.g., (Wagner et al., 2007; Baumgarten et al., 2018)). It has been shown that if secretory protein production 
results in saturation of the secretory apparatus the heat shock response is activated to clear mis-targeted and -folded proteins and increase the protein (re)folding capacity of the cell (e.g., (Wagner et al., 2007; Baumgarten et al., 2018)). Using the Lemo21(DE3) strain it has been shown that harmonizing the production rate of a secretory protein with the capacity of the secretory apparatus can result in cells that have a proteome composition that is similar to the proteome composition of non-producing cells (Baumgarten et al., 2018).

In the section "Tuning transcription and translation", it was described how hGH was produced using the rhamnose promoter in a rha operon deletion strain background at varying concentrations of rhamnose and four different signal peptides. Cells producing hGH in the periplasm at the highest level, for each of the four signal peptides used, were analyzed using proteomics (Karyolaimos et al., 2020). Irrespective of the signal peptide used, the accumulation levels of SecA, LepB and YidC were increased. Thus, enhancing periplasmic hGH production using the rhamnose promoter in a rha operon deletion strain background leads to increased Sec-translocon capacity, increased capacity to cleave signal peptides from secretory proteins and an increased capacity of an alternative membrane protein biogenesis pathway, thereby freeing up Sec-translocon capacity for protein secretion. When cells with enhanced periplasmic hGH production yields were harvested and subsequently cultured in the absence of inducer, SecA, LepB, and YidC accumulation levels went down again. This indicates that $E$. coli can adapt its protein secretory apparatus for enhanced recombinant protein production in the periplasm. The gene encoding SecA is in an operon preceded by the gene encoding SecM, which is a secretion monitor (Ito et al., 2018). SecM is encoded by the $5^{\prime}$ region of the secM-secA mRNA. SecM translation is subject to transient elongation arrest, which is prolonged when the secretion of the nascent SecM is hampered. This results in disrupting the secondary structure of the secM-secA mRNA by the stalled ribosome such that the ribosome binding site of secA becomes available leading to the synthesis of SecA to relieve the export defect. Unfortunately, we have only limited knowledge on how LepB and YidC accumulation levels are regulated. At any rate, optimizing periplasmic protein production yields can also lead to adaptations that make the $E$. coli cell a more efficient protein factory.

It has been shown that the accumulation levels of phage shock protein $\mathrm{A}(\mathrm{PspA})$ can increase upon the production of a protein in the periplasm (Champion et al., 2003). PspA is encoded by the phage shock protein ( $p s p$ ) operon ( $p s p A B C D E$ ) which plays a key role in maintaining membrane integrity and the proton-motive force under various stress conditions (Mitchell and Silhavy, 2019). Interestingly, co-production of PspA can enhance both Sec- and Tat-mediated protein export (Champion et al., 2003; DeLisa et al., 2004). It is tempting to speculate that increased PspA accumulation levels can make E. coli more fit for efficient periplasmic protein production by maintaining the integrity of the cytoplasmic membrane and the proton-motive force (Mitchell and Silhavy, 2019).

Finally, to facilitate the adaptation of E. coli for the production of a protein in the periplasm an approach called global transcriptional machinery engineering (gTME) has been used (McKenna et al., 2019). More specifically, to enhance the production of full length antibodies in the periplasm a mutant library of the principal sigma factor RpoD, a. k.a. $\sigma^{70}$, was co-produced with the protein. For the sake of clarity, it should be mentioned that the cells still had an intact wild-type $r p o D$ gene. Various RpoD variants were isolated that helped to increase full length antibody production in the periplasm. Transcriptome analysis showed that the RpoD variants altered the transcriptomes significantly, but did not really help to reveal why in cells with the RpoD variants production of full length antibodies in the periplasm was enhanced.

\section{CONCLUDING REMARKS AND FUTURE PERSPECTIVES}

Many different strategies have been used to enhance periplasmic protein production yields in E. coli. Usually, these are based on changing one parameter or variable at a time. So far, combinatorial screens, i.e., screens changing different parameters or variables simultaneously, have hardly been used (Eichmann et al., 2019; Karyolaimos et al., 2019). New technologies and methodologies facilitating largescale culturing and monitoring protein production levels will greatly facilitate combinatorial screening using different strains, expression vectors, signal peptides, induction regimes, culturing methods and conditions (Krause et al., 2016; Tripathi and Shrivastava, 2019; Kastenhofer et al., 2021). Tunable and independently controlled promoter setups, like the ones of the recently developed "Marionette" strain/expression vector collection, as well as CRISPR-based gene regulators have tremendous potential to facilitate combinatorial co-production screening (Meyer et al., 2019; Reis et al., 2019; Ho et al., 2020). The "Marionette" promoter setups and CRISPR-based gene regulators enable screening for the impact on periplasmic protein production using a myriad of different expression intensities of the gene encoding the recombinant protein and the gene encoding the co-produced component. Usually, one and sometimes two components are co-produced at a time, whereas co-production of multiple $(>2)$ components may actually be needed to further enhance production yields. With the current DNA synthesis and cloning technologies, it should not be difficult to engineer versatile expression vector library setups for multi-component co-production strategies (Hughes and Ellington, 2017). Aforementioned "Marionette" promoter setups and CRISPR-based gene regulators will enable tunable and independently controlled expression of the genes encoding all actors involved. The co-production of components can also have indirect positive effects on periplasmic protein production yields (Ow et al., 2010). Furthermore, it has been shown that (the co-production of) variants of components involved in the protein biogenesis can also help to improve periplasmic protein production yields (Pérez-Pérez et al., 1994; Taw et al., 2021). Isolation of such variants will require cleverly designed screens or selections. Also hosts can be customized for the production of a particular 
recombinant protein in the periplasm using evolutionary and engineering approaches (Wang et al., 2009; Robertson et al., 2021; Wannier et al., 2021).

It should not be forgotten that our knowledge of gene expression, protein translation, protein targeting, translocation, folding and stability is everything but complete. Furthering our knowledge in these areas may also open up new avenues for enhancing periplasmic protein production yields. Studying E. coli cells producing proteins in the periplasm using omics approaches, may help to identify components that can positively and also negatively affect periplasmic protein production yields (e.g., (Ceroni et al., 2015; Reis et al., 2019; Karyolaimos et al., 2020; Mateus et al., 2020; Tan et al., 2020; Rugbjerg et al., 2021)). Such studies may extend the repertoire of components that can be coproduced and used for the isolation of variants as well as genes that can be inactivated to enhance periplasmic protein production yields.

Taken together, different strategies have successfully been used to enhance periplasmic protein production yields in E. coli and there appears to be ample room for further improvements. The more information becomes available, the easier it may become to develop predictors and other computer-aided tools that can assist in designing strategies to enhance periplasmic protein production yields (Salis et al., 2009; Orfanoudaki et al., 2017; Almagro Armenteros et al., 2019; Reis and Salis, 2020; Bhandari et al., 2021; Cetnar and Salis, 2021).

\section{REFERENCES}

Akiyama, Y., and Ito, K. (1990). SecY Protein, a Membrane-Embedded Secretion Factor of E. coli, Is Cleaved by the ompT Protease In Vitro. Biochem. Biophysical Res. Commun. 167 (2), 711-715. doi:10.1016/0006-291x(90)92083-c

Alanen, H. I., Walker, K. L., Lourdes Velez Suberbie, M., Matos, C. F. R. O., Bönisch, S., Freedman, R. B., et al. (2015). Efficient export of Human Growth Hormone, Interferon $\mathrm{a} 2 \mathrm{~b}$ and Antibody Fragments to the Periplasm by the Escherichia coli Tat Pathway in the Absence of Prior Disulfide Bond Formation. Biochim. Biophys. Acta (Bba) - Mol. Cel Res. 1853 (3), 756-763. doi:10.1016/ j.bbamcr.2014.12.027

Almagro Armenteros, J. J., Tsirigos, K. D., Sønderby, C. K., Petersen, T. N., Winther, O., Brunak, S., et al. (2019). SignalP 5.0 Improves Signal Peptide Predictions Using Deep Neural Networks. Nat. Biotechnol. 37 (4), 420-423. doi:10.1038/s41587-019-0036-Z

Baars, L., Ytterberg, A. J., Drew, D., Wagner, S., Thilo, C., van Wijk, K. J., et al. (2006). Defining the Role of the Escherichia coli Chaperone SecB Using Comparative Proteomics. J. Biol. Chem. 281 (15), 10024-10034. doi:10.1074/ jbc.M509929200

Baumgarten, T., Ytterberg, A. J., Zubarev, R. A., and de Gier, J.-W. (2018). Optimizing Recombinant Protein Production in the Escherichia coli Periplasm Alleviates Stress. Appl. Environ. Microbiol. 84 (12), e00270. doi:10.1128/AEM.00270-18

Becker, A. B., and Roth, R. A. (1992). An Unusual Active Site Identified in a Family of Zinc Metalloendopeptidases. Proc. Natl. Acad. Sci. 89 (9), 3835-3839. doi:10.1073/pnas.89.9.3835

Bhandari, B. K., Lim, C. S., and Gardner, P. P. (2021). TISIGNER.com: Web Services for Improving Recombinant Protein Production. Nucleic Acids Res. 49 (W1), W654-W661. doi:10.1093/nar/gkab175

Browning, D. F., Richards, K. L., Peswani, A. R., Roobol, J., Busby, S. J. W., and Robinson, C. (2017). Escherichia coli "TatExpress" Strains Super-secrete Human Growth Hormone into the Bacterial Periplasm by the Tat Pathway. Biotechnol. Bioeng. 114 (12), 2828-2836. doi:10.1002/bit.26434
Finally, we still can learn a lot from how Genentech capitalized on decades of work on the lac operon to produce insulin in E. coli, but also from its contributions to the field of periplasmic protein production (e.g., (Goeddel et al., 1979; Chang et al., 1987; Joly et al., 1998; Champion et al., 2001; Champion et al., 2003; Chen et al., 2004; Zhou et al., 2016; McKenna et al., 2019)). The many contributions Genentech has made to this field are based on systematically designed studies that show the benefits of standardization and the importance of considering scalability early on.

\section{AUTHOR CONTRIBUTIONS}

AK and J-WG wrote the paper.

\section{FUNDING}

This work was supported by grants from the Swedish Research Council (2019-04143), the Carl Tryggers Foundation (CTS19:78) and the NOVO NORDISK FOUNDATION (NNF19OC0057673) to J-WG, a Marie Curie Initial Training Network grant (Horizon 2020; ProteinFactory, 642863) to Stockholm University (AK). Funders have supported research in the lab.

Ceroni, F., Algar, R., Stan, G.-B., and Ellis, T. (2015). Quantifying Cellular Capacity Identifies Gene Expression Designs with Reduced burden. Nat. Methods 12 (5), 415-418. doi:10.1038/Nmeth.3339

Cetnar, D. P., and Salis, H. M. (2021). Systematic Quantification of Sequence and Structural Determinants Controlling mRNA Stability in Bacterial Operons. ACS Synth. Biol. 10 (2), 318-332. doi:10.1021/acssynbio.0c00471

Chamberlin, M., McGrath, J., and Waskell, L. (1970). New RNA Polymerase from Escherichia coli Infected with Bacteriophage T7. Nature 228 (5268), 227-231. doi: $10.1038 / 228227 \mathrm{a} 0$

Champion, K. M., Nishihara, J. C., Aldor, I. S., Moreno, G. T., Andersen, D., Stults, K. L., et al. (2003). Comparison of the Escherichia coli Proteomes for Recombinant Human Growth Hormone Producing and Nonproducing Fermentations. Proteomics 3 (7), 1365-1373. doi:10.1002/pmic.200300430

Champion, K. M., Nishihara, J. C., Joly, J. C., and Arnott, D. (2001). Similarity of the Escherichia coli Proteome upon Completion of Different Biopharmaceutical Fermentation Processes. Proteomics 1 (9), 1133-1148. doi:10.1002/16159861(200109)1:9<1133:Aid-Prot1133>3.0.Co;2-S

Chang, C. N., Rey, M., Bochner, B., Heyneker, H., and Gray, G. (1987). High-level Secretion of Human Growth Hormone by Escherichia coli. Gene 55 (2-3), 189-196. doi:10.1016/0378-1119(87)90279-4

Chatzi, K. E., Sardis, M. F., Tsirigotaki, A., Koukaki, M., Šoštarić, N., Konijnenberg, A., et al. (2017). Preprotein Mature Domains Contain Translocase Targeting Signals that Are Essential for Secretion. J. Cel Biol. 216 (5), 1357-1369. doi:10.1083/jcb.201609022

Chen, C., Snedecor, B., Nishihara, J. C., Joly, J. C., McFarland, N., Andersen, D. C., et al. (2004). High-level Accumulation of a Recombinant Antibody Fragment in the Periplasm of Escherichia coli Requires a Triple-Mutant (degP Prc Spr) Host Strain. Biotechnol. Bioeng. 85 (5), 463-474. doi:10.1002/bit.20014

Chen, H., KIm, J., and Kendall, D. A. (1996). Competition between Functional Signal Peptides Demonstrates Variation in Affinity for the Secretion Pathway. J. Bacteriol. 178 (23), 6658-6664. doi:10.1128/jb.178.23.6658-6664.1996

Cheng, Y. S., Zipser, D., Cheng, C. Y., and Rolseth, S. J. (1979). Isolation and Characterization of Mutations in the Structural Gene for Protease III (Ptr). J. Bacteriol. 140 (1), 125-130. doi:10.1128/jb.140.1.125-130.1979 
Cohen, S. N., Chang, A. C. Y., Boyer, H. W., and Helling, R. B. (1973). Construction of Biologically Functional Bacterial Plasmids In Vitro. Proc. Natl. Acad. Sci. 70 (11), 3240-3244. doi:10.1073/pnas.70.11.3240

Conlin, C. A., Trun, N. J., Silhavy, T. J., and Miller, C. G. (1992). Escherichia coli prlC Encodes an Endopeptidase and Is Homologous to the Salmonella typhimurium opdA Gene. J. Bacteriol. 174 (18), 5881-5887. doi:10.1128/ jb.174.18.5881-5887.1992

Crea, R., Kraszewski, A., Hirose, T., and Itakura, K. (1978). Chemical Synthesis of Genes for Human Insulin. Proc. Natl. Acad. Sci. 75 (12), 5765-5769. doi:10.1073/pnas.75.12.5765

Dalbey, R. E., Wang, P., and van Dijl, J. M. (2012). Membrane Proteases in the Bacterial Protein Secretion and Quality Control Pathway. Microbiol. Mol. Biol. Rev. 76 (2), 311-330. doi:10.1128/Mmbr.05019-11

De Geyter, J., Portaliou, A. G., Srinivasu, B., Krishnamurthy, S., Economou, A., and Karamanou, S. (2020). Trigger Factor Is a Bona Fide Secretory Pathway Chaperone that Interacts with SecB and the Translocase. EMBO Rep. 21 (6), e49054. doi:10.15252/embr.201949054

De Geyter, J., Tsirigotaki, A., Orfanoudaki, G., Zorzini, V., Economou, A., and Karamanou, S. (2016). Protein Folding in the Cell Envelope of Escherichia coli. Nat. Microbiol. 1 (8), 16107. doi:10.1038/nmicrobiol.2016.107

DeLisa, M. P., Lee, P., Palmer, T., and Georgiou, G. (2004). Phage Shock Protein PspA of Escherichia coli Relieves Saturation of Protein export via the Tat Pathway. J. Bacteriol. 186 (2), 366-373. doi:10.1128/Jb.186.2.366373.2004

DeLisa, M. P., Tullman, D., and Georgiou, G. (2003). Folding Quality Control in the export of Proteins by the Bacterial Twin-Arginine Translocation Pathway. Proc. Natl. Acad. Sci. 100 (10), 6115-6120. doi:10.1073/pnas.0937838100

Ding, L., Becker, A. B., Suzuki, A., and Roth, R. A. (1992). Comparison of the Enzymatic and Biochemical Properties of Human Insulin-Degrading Enzyme and Escherichia coli Protease III. J. Biol. Chem. 267 (4), 2414-2420. doi:10.1016/ s0021-9258(18)45895-4

Eichmann, J., Oberpaul, M., Weidner, T., Gerlach, D., and Czermak, P. (2019). Selection of High Producers from Combinatorial Libraries for the Production of Recombinant Proteins in Escherichia coli and Vibrio Natriegens. Front. Bioeng. Biotechnol. 7, 254. doi:10.3389/fbioe.2019.00254

Ellis, M., and Humphreys, D. P. (2014). Bacterial Host Strain Expressing Recombinant DsbC. US 2014/0141468 A1.

Ellis, M., Patel, P., Edon, M., Ramage, W., Dickinson, R., and Humphreys, D. P. (2017). Development of a High yielding E. coli periplasmic Expression System for the Production of Humanized Fab' Fragments. Biotechnol. Prog. 33 (1), 212-220. doi:10.1002/btpr.2393

Emr, S. D., Hanley-Way, S., and Silhavy, T. J. (1981). Suppressor Mutations that Restore Export of a Protein with a Defective Signal Sequence. Cell 23 (1), 79-88. doi:10.1016/0092-8674(81)90272-5

Endo, S., Yamamoto, Y., Sugawara, T., Nishimura, O., and Fujino, M. (2001). The Additional Methionine Residue at the N-Terminus of Bacterially Expressed Human Interleukin-2 Affects the Interaction between the $\mathrm{N}$ - and C-Termini. Biochemistry 40 (4), 914-919. doi:10.1021/bi001170r

Frain, K. M., Robinson, C., and van Dijl, J. M. (2019). Transport of Folded Proteins by the Tat System. Protein J. 38 (4), 377-388. doi:10.1007/s10930-019-09859-y

Fraser, T. H., and Bruce, B. J. (1978). Chicken Ovalbumin Is Synthesized and Secreted by Escherichia coli. Proc. Natl. Acad. Sci. 75 (12), 5936-5940. doi:10.1073/pnas.75.12.5936

Frottin, F., Martinez, A., Peynot, P., Mitra, S., Holz, R. C., Giglione, C., et al. (2006). The Proteomics of N-Terminal Methionine Cleavage. Mol. Cell Proteomics 5 (12), 2336-2349. doi:10.1074/mcp.M600225-MCP200

Gaciarz, A., Veijola, J., Uchida, Y., Saaranen, M. J., Wang, C., Hörkkö, S., et al. (2016). Systematic Screening of Soluble Expression of Antibody Fragments in the Cytoplasm of E. coli. Microb. Cel Fact 15, 22. doi:10.1186/s12934-0160419-5

Gao, W., Yin, J., Bao, L., Wang, Q., Hou, S., Yue, Y., et al. (2018). Engineering Extracellular Expression Systems in Escherichia coli Based on Transcriptome Analysis and Cell Growth State. ACS Synth. Biol. 7 (5), 1291-1302. doi:10.1021/ acssynbio.7b00400

Gawin, A., Ertesvåg, H., Hansen, S. A. H., Malmo, J., and Brautaset, T. (2020). Translational Regulation of Periplasmic Folding Assistants and Proteases as a Valuable Strategy to Improve Production of Translocated Recombinant
Proteins in Escherichia coli. BMC Biotechnol. 20 (1), 24. doi:10.1186/s12896020-00615-0

Giacalone, M. J., Gentile, A. M., Lovitt, B. T., Berkley, N. L., Gunderson, C. W., and Surber, M. W. (2006). Toxic Protein Expression in Escherichia coli Using a Rhamnose-Based Tightly Regulated and Tunable Promoter System. Biotechniques 40 (3), 355-364. doi:10.2144/000112112

Goeddel, D. V., Kleid, D. G., Bolivar, F., Heyneker, H. L., Yansura, D. G., Crea, R., et al. (1979). Expression in Escherichia coli of Chemically Synthesized Genes for Human Insulin. Proc. Natl. Acad. Sci. 76 (1), 106-110. doi:10.1073/ pnas.76.1.106

Goodman, D. B., Church, G. M., and Kosuri, S. (2013). Causes and Effects of N-Terminal Codon Bias in Bacterial Genes. Science 342 (6157), 475-479. doi:10.1126/science. 1241934

Gottesman, S. (1996). Proteases and Their Targets in Escherichia coli. Annu. Rev. Genet. 30, 465-506. doi:10.1146/annurev.genet.30.1.465

Grodberg, J., and Dunn, J. J. (1988). ompT Encodes the Escherichia coli Outer Membrane Protease that Cleaves T7 RNA Polymerase during Purification. J. Bacteriol. 170 (3), 1245-1253. doi:10.1128/jb.170.3.1245-1253.1988

Guerrero Montero, I., Richards, K. L., Jawara, C., Browning, D. F., Peswani, A. R., Labrit, M., et al. (2019). Escherichia coli "TatExpress" Strains export Several G/L Human Growth Hormone to the Periplasm by the Tat Pathway. Biotechnol. Bioeng. 116 (12), 3282-3291. doi:10.1002/bit.27147

Hegde, R. S., and Bernstein, H. D. (2006). The Surprising Complexity of Signal Sequences. Trends Biochem. Sci. 31 (10), 563-571. doi:10.1016/ j.tibs.2006.08.004

Hjelm, A., Karyolaimos, A., Zhang, Z., Rujas, E., Vikström, D., Slotboom, D. J., et al. (2017). Tailoring Escherichia coli for the L-Rhamnose $\mathrm{P}_{\mathrm{BAD}}$ Promoter-Based Production of Membrane and Secretory Proteins. ACS Synth. Biol. 6 (6), 985-994. doi:10.1021/acssynbio.6b00321

Ho, H. I., Fang, J. R., Cheung, J., and Wang, H. H. (2020). Programmable CRISPRCas Transcriptional Activation in Bacteria. Mol. Syst. Biol. 16 (7), e9427. doi:10.15252/msb.20199427

Horga, L. G., Halliwell, S., Castiñeiras, T. S., Wyre, C., Matos, C. F. R. O., Yovcheva, D. S., et al. (2018). Tuning Recombinant Protein Expression to Match Secretion Capacity. Microb. Cel Fact 17, 199. doi:10.1186/s12934-018-1047-Z

Hsiung, H. M., Cantrell, A., Luirink, J., Oudega, B., Veros, A. J., and Becker, G. W. (1989). Use of Bacteriocin Release Protein in E. coli for Excretion of Human Growth Hormone into the Culture Medium. Nat. Biotechnol. 7 (3), 267-271. doi: $10.1038 /$ nbt0389-267

Hu, X., O’Hara, L., White, S., Magner, E., Kane, M., and Gerard Wall, J. (2007). Optimisation of Production of a Domoic Acid-Binding scFv Antibody Fragment in Escherichia coli Using Molecular Chaperones and Functional Immobilisation on a Mesoporous Silicate Support. Protein Expr. Purif. 52 (1), 194-201. doi:10.1016/j.pep.2006.08.009

Hughes, R. A., and Ellington, A. D. (2017). Synthetic DNA Synthesis and Assembly: Putting the Synthetic in Synthetic Biology. Cold Spring Harb Perspect. Biol. 9 (1), a023812. doi:10.1101/cshperspect.a023812

Hughes, S. S. (2011). Genentech: The Beginnings of Biotech. Chicago Ill, London, UK: University of Chicago Press.

Humphreys, D. P., Sehdev, M., Chapman, A. P., Ganesh, R., Smith, B. J., King, L. M., et al. (2000). High-Level Periplasmic Expression in Escherichia coli Using a Eukaryotic Signal Peptide: Importance of Codon Usage at the $5^{\prime}$ End of the Coding Sequence. Protein Expr. Purif. 20 (2), 252-264. doi:10.1006/ prep.2000.1286

Itakura, K., Hirose, T., Crea, R., Riggs, A. D., Heyneker, H. L., Bolivar, F., et al. (1977). Expression in Escherichia coli of a Chemically Synthesized Gene for the Hormone Somatostatin. Science 198 (4321), 1056-1063. doi:10.1126/ science. 412251

Ito, K., and Akiyama, Y. (2005). Cellular Functions, Mechanism of Action, and Regulation of FtsH Protease. Annu. Rev. Microbiol. 59, 211-231. doi:10.1146/ annurev.micro.59.030804.121316

Ito, K., Mori, H., and Chiba, S. (2018). Monitoring Substrate Enables Real-Time Regulation of a Protein Localization Pathway. FEMS Microbiol. Lett. 365 (11). doi:10.1093/femsle/fny109

Izard, J. W., and Kendall, D. A. (1994). Signal Peptides: Exquisitely Designed Transport Promoters. Mol. Microbiol. 13 (5), 765-773. doi:10.1111/j.13652958.1994.tb00469.x 
Jackson, D. A., Symons, R. H., and Berg, P. (1972). Biochemical Method for Inserting New Genetic Information into DNA of Simian Virus 40: Circular SV40 DNA Molecules Containing Lambda Phage Genes and the Galactose Operon of Escherichia coli. Proc. Natl. Acad. Sci. 69 (10), 2904-2909. doi:10.1073/pnas.69.10.2904

Jeong, H., Barbe, V., Lee, C. H., Vallenet, D., Yu, D. S., Choi, S.-H., et al. (2009). Genome Sequences of Escherichia coli B Strains REL606 and BL21(DE3). J. Mol. Biol. 394 (4), 644-652. doi:10.1016/j.jmb.2009.09.052

Jeong, H., Kim, H. J., and Lee, S. J. (2015). Complete Genome Sequence of Escherichia coli Strain BL21. Genome Announc 3 (2), e00134. doi:10.1128/ genomeA.00134-15

Jiang, C., Wynne, M., and Huber, D. (2021). How Quality Control Systems AID Sec-dependent Protein Translocation. Front. Mol. Biosci. 8, 669376. doi:10.3389/fmolb.2021.669376

Joly, J. C., Leung, W. S., and Swartz, J. R. (1998). Overexpression of Escherichia coli Oxidoreductases Increases Recombinant Insulin-like Growth Factor-I Accumulation. Proc. Natl. Acad. Sci. 95 (6), 2773-2777. doi:10.1073/ pnas.95.6.2773

Kadokura, H., and Beckwith, J. (2009). Detecting Folding Intermediates of a Protein as it Passes through the Bacterial Translocation Channel. Cell 138 (6), 1164-1173. doi:10.1016/j.cell.2009.07.030

Karyolaimos, A., Ampah-Korsah, H., Hillenaar, T., Mestre Borras, A., Dolata, K. M., Sievers, S., et al. (2019). Enhancing Recombinant Protein Yields in the E. coli Periplasm by Combining Signal Peptide and Production Rate Screening. Front. Microbiol. 10, 1511. doi:10.3389/fmicb.2019.01511

Karyolaimos, A., Dolata, K. M., Antelo-Varela, M., Mestre Borras, A., Elfageih, R., Sievers, S., et al. (2020). Escherichia coli Can Adapt its Protein Translocation Machinery for Enhanced Periplasmic Recombinant Protein Production. Front. Bioeng. Biotechnol. 7, 465. doi:10.3389/fbioe.2019.00465

Kastenhofer, J., Rajamanickam, V., Libiseller-Egger, J., and Spadiut, O. (2021). Monitoring and Control of E. coli Cell Integrity. J. Biotechnol. 329, 1-12. doi:10.1016/j.jbiotec.2021.01.009

Keiler, K. C., and Sauer, R. T. (1996). Sequence Determinants of C-Terminal Substrate Recognition by the Tsp Protease. J. Biol. Chem. 271 (5), 2589-2593. doi:10.1074/jbc.271.5.2589

Kendall, D. A., Bock, S. C., and Kaiser, E. T. (1986). Idealization of the Hydrophobic Segment of the Alkaline Phosphatase Signal Peptide. Nature 321 (6071), 706-708. doi:10.1038/321706a0

Kihara, A., Akiyama, Y., and Ito, K. (1995). FtsH Is Required for Proteolytic Elimination of Uncomplexed Forms of SecY, an Essential Protein Translocase Subunit. Proc. Natl. Acad. Sci. 92 (10), 4532-4536. doi:10.1073/pnas.92.10.4532

Kim, J., Rusch, S., Luirink, J., and Kendall, D. A. (2001). Is Ffh Required for export of Secretory Proteins? FEBS Lett. 505 (2), 245-248. doi:10.1016/S0014-5793(01) 02784-3

Kramer, R. A., Vandeputte-Rutten, L., de Roon, G. J., Gros, P., Dekker, N., and Egmond, M. R. (2001). Identification of Essential Acidic Residues of Outer Membrane Protease OmpT Supports a Novel Active Site. FEBS Lett. 505 (3), 426-430. doi:10.1016/s0014-5793(01)02863-0

Krause, M., Neubauer, A., and Neubauer, P. (2016). The Fed-Batch Principle for the Molecular Biology Lab: Controlled Nutrient Diets in Ready-Made media Improve Production of Recombinant Proteins in Escherichia coli. Microb. Cel Fact 15, 110. doi:10.1186/s12934-016-0513-8

Kulmala, A., Huovinen, T., and Lamminmäki, U. (2019). Improvement of Fab Expression by Screening Combinatorial Synonymous Signal Sequence Libraries. Microb. Cel Fact 18 (1), 157. doi:10.1186/s12934-019-1210-1

Laskowska, E., Kuczyńska-Wiśnik, D., Skórko-Glonek, J., and Taylor, A. (1996). Degradation by Proteases Lon, Clp and HtrA, of Escherichia coli Proteins Aggregated In Vivo by Heat Shock; HtrA Protease Action In Vivo and In Vitro. Mol. Microbiol. 22 (3), 555-571. doi:10.1046/j.13652958.1996.1231493.x

Lee, Y. J., Kim, H. S., Ryu, A. J., and Jeong, K. J. (2013). Enhanced Production of Full-Length Immunoglobulin G via the Signal Recognition Particle (SRP)dependent Pathway in Escherichia coli. J. Biotechnol. 165 (2), 102-108. doi:10.1016/j.jbiotec.2013.03.007

Liao, Y.-D., Jeng, J.-C., Wang, C.-F., Wang, S.-C., and Chang, S.-T. (2004). Removal of N-Terminal Methionine from Recombinant Proteins by engineered E. coli methione Aminopeptidase. Protein Sci. 13 (7), 1802-1810. doi:10.1110/ ps.04679104
Liao, Y.-D., Wang, S. C., Leu, Y. J., Wang, C. F., Chang, S. T., Hong, Y. T., et al. (2003). The Structural Integrity Exerted by N-Terminal Pyroglutamate Is Crucial for the Cytotoxicity of Frog Ribonuclease from Rana pipiens. Nucleic Acids Res. 31 (18), 5247-5255. doi:10.1093/nar/gkg746

Lycklama a Nijeholt, J. A., de Keyzer, J., Prabudiansyah, I., and Driessen, A. J. M. (2013). Characterization of the Supporting Role of SecE in Protein Translocation. FEBS Lett. 587 (18), 3083-3088. doi:10.1016/ j.febslet.2013.07.046

Makino, T., Skretas, G., and Georgiou, G. (2011a). Strain Engineering for Improved Expression of Recombinant Proteins in Bacteria. Microb. Cel Fact 10, 32. doi:10.1186/1475-2859-10-32

Makino, T., Skretas, G., Kang, T.-H., and Georgiou, G. (2011b). Comprehensive Engineering of Escherichia coli for Enhanced Expression of IgG Antibodies. Metab. Eng. 13 (2), 241-251. doi:10.1016/j.ymben.2010.11.002

Manta, B., Boyd, D., and Berkmen, M. (2019). Disulfide Bond Formation in the Periplasm of Escherichia coli. EcoSal Plus 8 (2), 1. doi:10.1128/ecosalplus.ESP0012-2018

Mateus, A., Hevler, J., Bobonis, J., Kurzawa, N., Shah, M., Mitosch, K., et al. (2020). The Functional Proteome Landscape of Escherichia coli. Nature 588 (7838), 473-478. doi:10.1038/s41586-020-3002-5

Matos, C. F. R. O., Robinson, C., Alanen, H. I., Prus, P., Uchida, Y., Ruddock, L. W., et al. (2014). Efficient export of Prefolded, Disulfide-Bonded Recombinant Proteins to the Periplasm by the Tat Pathway in Escherichia coli CyDisCo Strains. Biotechnol. Prog. 30 (2), 281-290. doi:10.1002/btpr.1858

Mavrangelos, C., Thiel, M., Adamson, P. J., Millard, D. J., Nobbs, S., Zola, H., et al. (2001). Increased Yield and Activity of Soluble Single-Chain Antibody Fragments by Combining High-Level Expression and the Skp Periplasmic Chaperonin. Protein Expr. Purif. 23 (2), 289-295. doi:10.1006/prep.2001.1506

McKenna, R., Lombana, T. N., Yamada, M., Mukhyala, K., and Veeravalli, K. (2019). Engineered Sigma Factors Increase Full-Length Antibody Expression in Escherichia coli. Metab. Eng. 52, 315-323. doi:10.1016/j.ymben.2018.12.009

Meerman, H. J., and Georgiou, G. (1994). Construction and Characterization of a Set of E. coli Strains Deficient in All Known Loci Affecting the Proteolytic Stability of Secreted Recombinant Proteins. Nat. Biotechnol. 12 (11), 1107-1110. doi:10.1038/nbt1194-1107

Meltzer, M., Hasenbein, S., Mamant, N., Merdanovic, M., Poepsel, S., Hauske, P., et al. (2009). Structure, Function and Regulation of the Conserved Serine Proteases DegP and DegS of Escherichia coli. Res. Microbiol. 160 (9), 660-666. doi:10.1016/j.resmic.2009.07.012

Merdanovic, M., Clausen, T., Kaiser, M., Huber, R., and Ehrmann, M. (2011). Protein Quality Control in the Bacterial Periplasm. Annu. Rev. Microbiol. 65, 149-168. doi:10.1146/annurev-micro-090110-102925

Mergulhão, F. J. M., Summers, D. K., and Monteiro, G. A. (2005). Recombinant Protein Secretion in Escherichia coli. Biotechnol. Adv. 23 (3), 177-202. doi:10.1016/j.biotechadv.2004.11.003

Meyer, A. J., Segall-Shapiro, T. H., Glassey, E., Zhang, J., and Voigt, C. A. (2019). Escherichia coli "Marionette" Strains with 12 Highly Optimized Small-Molecule Sensors. Nat. Chem. Biol. 15 (2), 196-204. doi:10.1038/s41589-018-0168-3

Miroux, B., and Walker, J. E. (1996). Over-production of Proteins in Escherichia coli: Mutant Hosts that Allow Synthesis of Some Membrane Proteins and Globular Proteins at High Levels. J. Mol. Biol. 260, 289-298. doi:10.1006/ jmbi.1996.0399

Mitchell, A. M., and Silhavy, T. J. (2019). Envelope Stress Responses: Balancing Damage Repair and Toxicity. Nat. Rev. Microbiol. 17 (7), 417-428. doi:10.1038/ s41579-019-0199-0

Moffatt, B. A., and Studier, F. W. (1987). T7 Lysozyme Inhibits Transcription by T7 RNA Polymerase. Cell 49 (2), 221-227. doi:10.1016/0092-8674(87)90563-0

Morra, R., Shankar, J., Robinson, C. J., Halliwell, S., Butler, L., Upton, M., et al. (2016). Dual Transcriptional-Translational cascade Permits Cellular Level Tuneable Expression Control. Nucleic Acids Res. 44 (3), e21. doi:10.1093/ nar/gkv912

Natarajan, A., Haitjema, C. H., Lee, R., Boock, J. T., and DeLisa, M. P. (2017). An Engineered Survival-Selection Assay for Extracellular Protein Expression Uncovers Hypersecretory Phenotypes in Escherichia coli. ACS Synth. Biol. 6 (5), 875-883. doi:10.1021/acssynbio.6b00366

Novak, P., and Dev, I. K. (1988). Degradation of a Signal Peptide by Protease IV and Oligopeptidase A. J. Bacteriol. 170 (11), 5067-5075. doi:10.1128/ jb.170.11.5067-5075.1988 
Orfanoudaki, G., Markaki, M., Chatzi, K., Tsamardinos, I., and Economou, A. (2017). MatureP: Prediction of Secreted Proteins with Exclusive Information from Their Mature Regions. Sci. Rep. 7 (1), 3263. doi:10.1038/s41598-01703557-4

Oswald, J., Njenga, R., Natriashvili, A., Sarmah, P., and Koch, H.-G. (2021). The Dynamic SecYEG Translocon. Front. Mol. Biosci. 8, 664241. doi:10.3389/ fmolb.2021.664241

Ow, D., Lim, D., Morin Nissom, P., Camattari, A., and Wong, V. (2010). Coexpression of Skp and FkpA Chaperones Improves Cell Viability and Alters the Global Expression of Stress Response Genes during scFvD1.3 Production. Microb. Cel Fact 9, 22. doi:10.1186/1475-2859-9-22

Paetzel, M. (2014). Structure and Mechanism of Escherichia coli Type I Signal Peptidase. Biochim. Biophys. Acta (Bba) - Mol. Cel Res. 1843 (8), 1497-1508. doi:10.1016/j.bbamcr.2013.12.003

Palmer, T., and Stansfeld, P. J. (2020). Targeting of Proteins to the Twin-arginine Translocation Pathway. Mol. Microbiol. 113 (5), 861-871. doi:10.1111/ mmi.14461

Pérez-Pérez, J., Márquez, G., Barbero, J.-L., and Gutiérrez, J. (1994). Increasing the Efficiency of Protein Export in Escherichia coli. Nat. Biotechnol. 12 (2), 178-180. doi:10.1038/nbt0294-178

Puertas, J.-M., Nannenga, B. L., Dornfeld, K. T., Betton, J.-M., and Baneyx, F. (2010). Enhancing the Secretory Yields of Leech Carboxypeptidase Inhibitor in Escherichia coli: Influence of Trigger Factor and Signal Recognition Particle. Protein Expr. Purif. 74 (1), 122-128. doi:10.1016/j.pep.2010.06.008

Reis, A. C., Halper, S. M., Vezeau, G. E., Cetnar, D. P., Hossain, A., Clauer, P. R., et al. (2019). Simultaneous Repression of Multiple Bacterial Genes Using Nonrepetitive Extra-long sgRNA Arrays. Nat. Biotechnol. 37 (11), 1294-1301. doi:10.1038/s41587-019-0286-9

Reis, A. C., and Salis, H. M. (2020). An Automated Model Test System for Systematic Development and Improvement of Gene Expression Models. ACS Synth. Biol. 9 (11), 3145-3156. doi:10.1021/acssynbio.0c00394

Rennig, M., Martinez, V., Mirzadeh, K., Dunas, F., Röjsäter, B., Daley, D. O., et al. (2018). TARSyn: Tunable Antibiotic Resistance Devices Enabling Bacterial Synthetic Evolution and Protein Production. ACS Synth. Biol. 7 (2), 432-442. doi:10.1021/acssynbio.7b00200

Robertson, W. E., Funke, L. F. H., de la Torre, D., Fredens, J., Wang, K., and Chin, J. W. (2021). Creating Custom Synthetic Genomes in Escherichia coli with REXER and GENESIS. Nat. Protoc. 16 (5), 2345-2380. doi:10.1038/s41596-02000464-3

Rugbjerg, P., Dyerberg, A. S. B., Quainoo, S., Munck, C., and Sommer, M. O. A. (2021). Short and Long-Read Ultra-deep Sequencing Profiles Emerging Heterogeneity across Five Platform Escherichia coli Strains. Metab. Eng. 65, 197-206. doi:10.1016/j.ymben.2020.11.006

Rusch, S. L., and Kendall, D. A. (1994). Transport of an Export-Defective Protein by a Highly Hydrophobic Signal Peptide. J. Biol. Chem. 269 (2), 1243-1248. doi:10.1016/s0021-9258(17)42249-6

Rusch, S., Mascolo, C., Kebir, M., and Kendall, D. (2002). Juxtaposition of SignalPeptide Charge and Core Region Hydrophobicity Is Critical for Functional Signal Peptides. Arch. Microbiol. 178 (4), 306-310. doi:10.1007/s00203-0020453-z

Sala, A., Bordes, P., and Genevaux, P. (2014). Multitasking SecB Chaperones in Bacteria. Front. Microbiol. 5, 666. doi:10.3389/fmicb.2014.00666

Salis, H. M., Mirsky, E. A., and Voigt, C. A. (2009). Automated Design of Synthetic Ribosome Binding Sites to Control Protein Expression. Nat. Biotechnol. 27 (10), 946-950. doi:10.1038/nbt.1568

Sargent, F., Bogsch, E. G., Stanley, N. R., Wexler, M., Robinson, C., Berks, B. C., et al. (1998). Overlapping Functions of Components of a Bacterial Secindependent Protein export Pathway. EMBO J. 17 (13), 3640-3650. doi:10.1093/emboj/17.13.3640

Schierle, C. F., Berkmen, M., Huber, D., Kumamoto, C., Boyd, D., and Beckwith, J. (2003). The DsbA Signal Sequence Directs Efficient, Cotranslational export of Passenger Proteins to the Escherichia coli Periplasm via the Signal Recognition Particle Pathway. J. Bacteriol. 185 (19), 5706-5713. doi:10.1128/jb.185.19.57065713.2003

Schlapschy, M., Grimm, S., and Skerra, A. (2006). A System for Concomitant Overexpression of Four Periplasmic Folding Catalysts to Improve Secretory Protein Production in Escherichia coli. Protein Eng. Des. Selection 19 (8), 385-390. doi:10.1093/protein/gzl018
Schlegel, S., Löfblom, J., Lee, C., Hjelm, A., Klepsch, M., Strous, M., et al. (2012). Optimizing Membrane Protein Overexpression in the Escherichia coli Strain Lemo21(DE3). J. Mol. Biol. 423 (4), 648-659. doi:10.1016/j.jmb.2012.07.019

Schlegel, S., Rujas, E., Ytterberg, A. J., Zubarev, R. A., Luirink, J., and de Gier, J.-W. (2013). Optimizing Heterologous Protein Production in the Periplasm of E. coli by Regulating Gene Expression Levels. Microb. Cel Fact 12, 24. doi:10.1186/ 1475-2859-12-24

Schmidt, A., Kochanowski, K., Vedelaar, S., Ahrné, E., Volkmer, B., Callipo, L., et al. (2016). The Quantitative and Condition-dependent Escherichia coli Proteome. Nat. Biotechnol. 34 (1), 104-110. doi:10.1038/nbt.3418

Selas Castiñeiras, T., Williams, S. G., Hitchcock, A., Cole, J. A., Smith, D. C., and Overton, T. W. (2018). Development of a Generic $\beta$-lactamase Screening System for Improved Signal Peptides for Periplasmic Targeting of Recombinant Proteins in Escherichia coli. Sci. Rep. 8, 6986. doi:10.1038/ s41598-018-25192-3

Shanmugaw, S. K., and Dalbey, R. E. (2019). The Conserved Role of YidC in Membrane Protein Biogenesis. Microbiol. Spectr. 7 (1), 1. doi:10.1128/ microbiolspec.PSIB-0014-2018

Sijbrandi, R., Urbanus, M. L., ten Hagen-Jongman, C. M., Bernstein, H. D., Oudega, B., Otto, B. R., et al. (2003). Signal Recognition Particle (SRP)-mediated Targeting and Sec-dependent Translocation of an Extracellular Escherichia coli Protein. J. Biol. Chem. 278 (7), 4654-4659. doi:10.1074/jbc.M211630200

Silverstone, A. E., Arditti, R. R., and Magasanik, B. (1970). Catabolite-insensitive Revertants of lac Promoter Mutants. Proc. Natl. Acad. Sci. 66 (3), 773-779. doi:10.1073/pnas.66.3.773

Simmons, L. C., and Yansura, D. G. (1996). Translational Level Is a Critical Factor for the Secretion of Heterologous Proteins in Escherichia coli. Nat. Biotechnol. 14 (5), 629-634. doi:10.1038/nbt0596-629

Singh, S. K., Parveen, S., SaiSree, L., and Reddy, M. (2015). Regulated Proteolysis of a Cross-link-specific Peptidoglycan Hydrolase Contributes to Bacterial Morphogenesis. Proc. Natl. Acad. Sci. USA 112 (35), 10956-10961. doi:10.1073/pnas.1507760112

Skórko-Glonek, J., Zurawa, D., Kuczwara, E., Wozniak, M., Wypych, Z., and Lipinska, B. (1999). The Escherichia coli Heat Shock Protease HtrA Participates in Defense against Oxidative Stress. Mol. Gen. Genet. 262 (2), 342-350. doi:10.1007/s004380051092

Smets, D., Loos, M. S., Karamanou, S., and Economou, A. (2019). Protein Transport across the Bacterial Plasma Membrane by the Sec Pathway. Protein J. 38 (3), 262-273. doi:10.1007/s10930-019-09841-8

Soltes, G. R., Martin, N. R., Park, E., Sutterlin, H. A., and Silhavy, T. J. (2017) Distinctive Roles for Periplasmic Proteases in the Maintenance of Essential Outer Membrane Protein Assembly. J. Bacteriol. 199 (20), e00418. doi:10.1128/ JB.00418-17

Sonoda, H., Kumada, Y., Katsuda, T., and Yamaji, H. (2011). Effects of Cytoplasmic and Periplasmic Chaperones on Secretory Production of Single-Chain Fv Antibody in Escherichia coli. J. Biosci. Bioeng. 111 (4), 465-470. doi:10.1016/ j.jbiosc.2010.12.015

Spiess, C., Beil, A., and Ehrmann, M. (1999). A Temperature-dependent Switch from Chaperone to Protease in a Widely Conserved Heat Shock Protein. Cell 97 (3), 339-347. doi:10.1016/S0092-8674(00)80743-6

Steiner, D., Forrer, P., Stumpp, M. T., and Plückthun, A. (2006). Signal Sequences Directing Cotranslational Translocation Expand the Range of Proteins Amenable to Phage Display. Nat. Biotechnol. 24 (7), 823-831. doi:10.1038/ nbt1218

Strauch, K. L., and Beckwith, J. (1988). An Escherichia coli Mutation Preventing Degradation of Abnormal Periplasmic Proteins. Proc. Natl. Acad. Sci. 85 (5), 1576-1580. doi:10.1073/pnas.85.5.1576

Strauch, K. L., Johnson, K., and Beckwith, J. (1989). Characterization of $\operatorname{deg} P$, a Gene Required for Proteolysis in the Cell Envelope and Essential for Growth of Escherichia coli at High Temperature. J. Bacteriol. 171 (5), 2689-2696. doi:10.1128/jb.171.5.2689-2696.1989

Studier, F. W., Daegelen, P., Lenski, R. E., Maslov, S., and Kim, J. F. (2009). Understanding the Differences between Genome Sequences of Escherichia coli B Strains REL606 and BL21(DE3) and Comparison of the E. coli B and K-12 Genomes. J. Mol. Biol. 394 (4), 653-680. doi:10.1016/j.jmb.2009.09.021

Studier, F. W., and Moffatt, B. A. (1986). Use of Bacteriophage T7 RNA Polymerase to Direct Selective High-Level Expression of Cloned Genes. J. Mol. Biol. 189 (1), 113-130. doi:10.1016/0022-2836(86)90385-2 
Stull, F., Betton, J.-M., and Bardwell, J. C. A. (2018). Periplasmic Chaperones and Prolyl Isomerases. EcoSal Plus 8 (1), 1. doi:10.1128/ecosalplus.ESP-0005-2018

Swamy, K. H. S., and Goldberg, A. L. (1981). E. coli Contains Eight Soluble Proteolytic Activities, One Being ATP Dependent. Nature 292 (5824), 652-654. doi:10.1038/292652a0

Talmadge, K., and Gilbert, W. (1982). Cellular Location Affects Protein Stability in Escherichia coli. Proc. Natl. Acad. Sci. 79 (6), 1830-1833. doi:10.1073/ pnas.79.6.1830

Talmadge, K., Kaufman, J., and Gilbert, W. (1980). Bacteria Mature Preproinsulin to Proinsulin. Proc. Natl. Acad. Sci. 77 (7), 3988-3992. doi:10.1073/ pnas.77.7.3988

Tan, J., Sastry, A. V., Fremming, K. S., Bjørn, S. P., Hoffmeyer, A., Seo, S., et al. (2020). Independent Component Analysis of E. coli's Transcriptome Reveals the Cellular Processes that Respond to Heterologous Gene Expression. Metab. Eng. 61, 360-368. doi:10.1016/j.ymben.2020.07.002

Taw, M. N., Li, M., Kim, D., Rocco, M. A., Waraho-Zhmayev, D., and DeLisa, M. P. (2021). Engineering a Supersecreting Strain of Escherichia coli by Directed Coevolution of the Multiprotein Tat Translocation Machinery. ACS Synth. Biol. 10 (11), 2947-2958. doi:10.1021/acssynbio.1c00183

Tripathi, N. K. (2016). Production and Purification of Recombinant Proteins from Escherichia coli. ChemBioEng Rev. 3 (3), 116-133. doi:10.1002/ cben. 201600002

Tripathi, N. K., and Shrivastava, A. (2019). Recent Developments in Bioprocessing of Recombinant Proteins: Expression Hosts and Process Development. Front. Bioeng. Biotechnol. 7, 420. doi:10.3389/fbioe.2019.00420

Tsirigotaki, A., Chatzi, K. E., Koukaki, M., De Geyter, J., Portaliou, A. G., Orfanoudaki, G., et al. (2018). Long-Lived Folding Intermediates Predominate the Targeting-Competent Secretome. Structure 26 (5), 695-707. doi:10.1016/j.str.2018.03.006

Tsirigotaki, A., De Geyter, J., Šoštaric', N., Economou, A., and Karamanou, S. (2017). Protein export through the Bacterial Sec Pathway. Nat. Rev. Microbiol. 15 (1), 21-36. doi:10.1038/nrmicro.2016.161

van der Wolk, J. P., Fekkes, P., Boorsma, A., Huie, J. L., Silhavy, T. J., and Driessen, A. J. (1998). PrlA4 Prevents the Rejection of Signal Sequence Defective Preproteins by Stabilizing the SecA-SecY Interaction during the Initiation of Translocation. EMBO J. 17 (18), 3631-3639. doi:10.1093/ emboj/17.13.3631

van Dijl, J. M., de Jong, A., Smith, H., Bron, S., and Venema, G. (1991). Signal Peptidase I Overproduction Results in Increased Efficiencies of export and Maturation of Hybrid Secretory Proteins in Escherichia coli. Mol. Gen. Genet. 227 (1), 40-48. doi:10.1007/Bf00260704

van Stelten, J., Silva, F., Belin, D., and Silhavy, T. J. (2009). Effects of Antibiotics and a Proto-Oncogene Homolog on Destruction of Protein Translocator SecY. Science 325 (5941), 753-756. doi:10.1126/science.1172221

Wagner, S., Baars, L., Ytterberg, A. J., Klussmeier, A., Wagner, C. S., Nord, O., et al. (2007). Consequences of Membrane Protein Overexpression in Escherichia coli. Mol. Cell Proteomics 6 (9), 1527-1550. doi:10.1074/mcp.m600431-mcp200
Wagner, S., Klepsch, M. M., Schlegel, S., Appel, A., Draheim, R., Tarry, M., et al. (2008). Tuning Escherichia coli for Membrane Protein Overexpression. Proc. Natl. Acad. Sci. 105 (38), 14371-14376. doi:10.1073/pnas.0804090105

Wang, H. H., Isaacs, F. J., Carr, P. A., Sun, Z. Z., Xu, G., Forest, C. R., et al. (2009). Programming Cells by Multiplex Genome Engineering and Accelerated Evolution. Nature 460 (7257), 894-898. doi:10.1038/nature08187

Wanner, B. L., Kodaira, R., and Neidhart, F. C. (1977). Physiological Regulation of a Decontrolled lac Operon. J. Bacteriol. 130 (1), 212-222. doi:10.1128/ jb.130.1.212-222.1977

Wannier, T. M., Ciaccia, P. N., Ellington, A. D., Filsinger, G. T., Isaacs, F. J., Javanmardi, K., et al. (2021). Recombineering and MAGE. Nat. Rev. Methods Primers 1 (1), 7. doi:10.1038/s43586-020-00006-x

Weiner, J. H., Bilous, P. T., Shaw, G. M., Lubitz, S. P., Frost, L., Thomas, G. H., et al. (1998). A Novel and Ubiquitous System for Membrane Targeting and Secretion of Cofactor-Containing Proteins. Cell 93 (1), 93-101. doi:10.1016/S00928674(00)81149-6

Zalucki, Y. M., Gittins, K. L., and Jennings, M. P. (2008). Secretory Signal Sequence Non-optimal Codons Are Required for Expression and export of $\beta$-lactamase. Biochem. Biophysical Res. Commun. 366 (1), 135-141. doi:10.1016/ j.bbrc.2007.11.093

Zalucki, Y. M., Jones, C. E., Ng, P. S. K., Schulz, B. L., and Jennings, M. P. (2010). Signal Sequence Non-optimal Codons Are Required for the Correct Folding of Mature Maltose Binding Protein. Biochim. Biophys. Acta (Bba) - Biomembranes 1798 (6), 1244-1249. doi:10.1016/j.bbamem.2010.03.010

Zhang, G., Brokx, S., and Weiner, J. H. (2006). Extracellular Accumulation of Recombinant Proteins Fused to the Carrier Protein YebF in Escherichia coli. Nat. Biotechnol. 24 (1), 100-104. doi:10.1038/nbt1174

Zhou, Y., Liu, P., Gan, Y., Sandoval, W., Katakam, A. K., Reichelt, M., et al. (2016) Enhancing Full-Length Antibody Production by Signal Peptide Engineering. Microb. Cel Fact 15, 47. doi:10.1186/s12934-016-0445-3

Conflict of Interest: The authors declare that the research was conducted in the absence of any commercial or financial relationships that could be construed as a potential conflict of interest.

Publisher's Note: All claims expressed in this article are solely those of the authors and do not necessarily represent those of their affiliated organizations, or those of the publisher, the editors, and the reviewers. Any product that may be evaluated in this article, or claim that may be made by its manufacturer, is not guaranteed or endorsed by the publisher.

Copyright $(02021$ Karyolaimos and de Gier. This is an open-access article distributed under the terms of the Creative Commons Attribution License (CC BY). The use, distribution or reproduction in other forums is permitted, provided the original author(s) and the copyright owner(s) are credited and that the original publication in this journal is cited, in accordance with accepted academic practice. No use, distribution or reproduction is permitted which does not comply with these terms. 